\title{
Bending of the concentration discharge relationship can inform about in-stream nitrate removal
}

\author{
Joni Dehaspe ${ }^{1}$, Fanny Sarrazin ${ }^{2}$, Rohini Kumar ${ }^{2}$, Jan H. Fleckenstein ${ }^{1,3}$ and Andreas Musolff ${ }^{1}$ \\ ${ }^{1}$ Department of Hydrogeology, UFZ- Helmholtz-Centre for Environmental Research, 04318 Leipzig, Germany \\ 5 2Department Computational Hydrosystems, UFZ - Helmholtz-Centre for Environmental Research, 04318 Leipzig, Germany \\ ${ }^{3}$ Bayreuth Center of Ecology and Environmental Research, University of Bayreuth, 95440 Bayreuth, Germany
}

Correspondence to: Joni Dehaspe (joni.dehaspe@ufz.de)

Abstract. Nitrate $\left(\mathrm{NO}_{3}^{-}\right)$excess in rivers harms aquatic ecosystems and can induce detrimental algae growths in coastal areas. Riverine $\mathrm{NO}_{3}^{-}$uptake is a crucial element of the catchment scale nitrogen balance and can be measured at small spatiotemporal

10 scales while at the scale of entire river networks, uptake measurements are rarely available. Concurrent, low frequency $\mathrm{NO}_{3}^{-}$ concentration and stream flow (Q) observations at a basin outlet, however, are commonly monitored and can be analyzed in terms of concentration discharge (C-Q) relationships. Previous studies suggest that more positive $\log (\mathrm{C})$ - $\log (\mathrm{Q})$ slopes under low flow conditions (than under high flows) are linked to biological $\mathrm{NO}_{3}^{-}$uptake, creating a bent rather than linear $\log (\mathrm{C})$ $\log (\mathrm{Q})$ relationship. Here we explore if network scale $\mathrm{NO}_{3}^{-}$uptake creates bent $\log (\mathrm{C})-\log (\mathrm{Q})$ relationships and when in turn

15 uptake can be quantified from observed low frequency C-Q data. To this end we apply a parsimonious mass balance based river network uptake model in 13 mesoscale German catchments (21-1450 $\left.\mathrm{km}^{2}\right)$ and explore the linkages between $\log (\mathrm{C})$ $\log (\mathrm{Q})$ bending and different model-parameter combinations. The modelling results show that uptake and transport in the river network can create bent $\log (\mathrm{C})-\log (\mathrm{Q})$ relationships at the basin outlet from $\log -\log \operatorname{linear} \mathrm{C}-\mathrm{Q}$ relationships describing the $\mathrm{NO}_{3}^{-}$land to stream transfer. We find that the bending is mainly shaped by geomorphological parameters that control the

20 channel reactive surface area rather than by the biological uptake velocity itself. Further we show that in this exploratory modelling environment, bending is positively correlated to percentage $\mathrm{NO}_{3}^{-}$load removed in the network $\left(L_{r . p e r c}\right)$ but that network wide flow velocities should be taken into account when interpreting $\log (\mathrm{C})-\log (\mathrm{Q})$ bending. Classification trees, finally, can successfully predict classes of low $(\sim 4 \%)$, intermediate $(\sim 32 \%)$ and high $(\sim 68 \%) L_{\text {r.perc }}$ using information on water velocity and $\log (\mathrm{C})-\log (\mathrm{Q})$ bending. These results can help to identify stream networks that efficiently attenuate $\mathrm{NO}_{3}^{-}$

25 loads based on low frequency $\mathrm{NO}_{3}^{-}$and $\mathrm{Q}$ observations and generally show the importance of the channel geomorphology on the emerging $\log (\mathrm{C})-\log (\mathrm{Q})$ bending at network scales.

\section{Introduction}

Transport and transformation of nitrate $\left(\mathrm{NO}_{3}^{-}\right)$in river networks are major controls of downstream exports to receiving lakes, reservoirs and coastal systems (Alexander et al., 2000; Billen et al., 1991; Peterson et al., 2001; Seitzinger et al., 2002; Seybold 
and McGlynn, 2018). Increased $\mathrm{NO}_{3}^{-}$concentrations in surface waters can induce detrimental algae growths (Beusen et al., 2016; Canfield et al., 2010; Galloway et al., 1995), compromise river ecosystem health and jeopardize drinking water supplies. Since the beginning of the $20^{\text {th }}$ century, human activities such as agricultural expansion and fossil fuel burning have mobilized additional reactive nitrogen $(\mathrm{N})$, initiating and later exacerbating this problem (Seitzinger et al., 2002). In arable landscapes, which include large parts of Europe, the efficient management of aquatic $\mathrm{NO}_{3}^{-}$at network scales is complicated by the spatiotemporal variability of loading patterns and hydrologic regimes as well as the lack of understanding of nutrient pathways, connected transit times and removal processes from input to export. Nevertheless, nitrate concentration and load variability can be predicted at catchment scales when relying on detailed process understanding regarding transport and biogeochemical processing (Alexander et al., 2009; Schlesinger et al., 2006; Wollheim et al., 2008). Moving beyond small scale variability and characterizing nitrate processing at the catchment scale however remains a challenge (McDonnell et al., 2007; Li et al., 2020).

Within river reaches and streams, reactive solutes like $\mathrm{NO}_{3}^{-}$are affected by complex interactions of physical, biological and chemical processes. Physical transport is driven by local discharge and channel geomorphology and dictates the $\mathrm{NO}_{3}^{-}$residence time in a reach, thus influencing the timescales at which biogeochemical processing can take place (Kirchner et al., 2000; Runkel and Bencala, 1995; Zarnetske et al., 2011). $\mathrm{NO}_{3}^{-}$is removed and transformed by denitrifying bacteria in the anoxic river sediment (Birgand et al., 2007; Peterson et al., 2001), ammonified or retained through assimilation processes in the oxic or anoxic river compartments by bacteria, fungi and primary producers such as algae and macrophytes, potentially entering higher trophic levels. In the latter case, $\mathrm{N}$ in the form of DON (dissolved organic nitrogen) and more commonly DIN (dissolved inorganic nitrogen), together with phosphorus (P) may be released to the water column later on (Durand et al., 2011; Vanni, 2002; Vanni and McIntyre, 2016). The nutrient spiraling model (Newbold et al., 1981; Stream Solute Workshop, 1990) that

50 formally describes these processes has been used to quantify and compare $\mathrm{NO}_{3}^{-}$transport and uptake (the net result of all removal and release processes) in river reaches (Peterson et al., 2001; Mulholland et al., 2008; Hall et al., 2009) and stream networks (Ensign et al., 2006; Doyle, 2005; Marce and Armengol, 2009). Quantifying in situ $\mathrm{NO}_{3}^{-}$uptake is labor intensive and may involve local nutrient additions, potentially altering the ambient uptake rate (Hensley et al., 2014; Mulholland and Tank, 2002). Other methods require high frequency measurements (Jarvie et al., 2018; Kunz et al., 2017) that are mostly

55 limited to small spatial scales (i.e. reach scale) and can vary considerably between measuring points (Boyer et al., 2006). At the scale of entire river networks contrarily, uptake measurements are rarely available (but see Wollheim et al., 2017; Hansen et al 2018) and models are applied instead to predict spatiotemporal uptake patterns (Boyer et al., 2006; Yang et al., 2018). These models account for the spatial configuration of the stream network, an important aspect for stream biogeochemistry that is often ignored in small scale experimental approaches (Fisher et al., 2004). Spatially distributed models however, require

60 calibration of uncertain spatiotemporal parameters and may not reflect the essential features of the system despite fitting observed data well (Klemes, 1986). 
River networks link terrestrial source zones to coastal areas and integrate biogeochemical and hydrological catchment functions across scales (Bouwman et al., 2012; Helton et al., 2018). Small streams (usually headwaters) are known to influence the export signal disproportionally because of their overall (high) contribution to total stream length and effective $\mathrm{NO}_{3}^{-}$removal capacity (Alexander et al., 2000; Horton, 1945), explained by high sediment surface to water volume ratios. Generally, high removal efficiencies have been reported for river network areas with lower specific discharges (Hall et al., 2009; Hensley et al., 2014), under favorable circumstances such as high light availability, heavy in-stream vegetation (Hensley et al., 2014; Rode et al., 2016) and for streams with a high capacity for lateral and hyporheic exchange (Gomez-Velez et al., 2015; Kiel and Cardenas, 2014). The scaling of in-stream uptake processes beyond the river reach has been approached by combined experimental-modelling studies with defined explicit scaling relationships (e.g. Basu et al., 2011; Aguilera et al., 2013; Bertuzzo et al., 2017; Lindgren and Destouni, 2004) and theoretical frameworks explaining how the river network capacity regulates solute export (e.g. Wollheim et al., 2018). Abbott et al. (2018) shows how spatially heterogeneous patterns of water chemistry stabilize while the temporal variability of nutrient concentrations persists when moving downstream, facilitating the temporal scaling of headwater measurements. Nevertheless, insights into linking the interplay of nitrate removal processes at the network scale to downstream export patterns in space and time are largely missing.

Concentrations (C) for in-stream solutes such as carbon, major ions, particulates and nutrients are commonly monitored concurrently with discharge $(\mathrm{Q})$ at the basin outlet. C-Q relationships integrate the effect of biogeochemical and hydrological processes within the catchment and have mainly been discussed in terms of land-stream transfer and source configuration in catchments as well as subsurface retention processes (Godsey et al., 2009; Musolff et al., 2017, Bieroza et al., 2018). The shape of long term (multiple years) C-Q relationships in the log-log space is typically described by the slope of a linear regression model (Godsey et al., 2009). Here, three archetypes have been distinguished; (i) a positive $\log (\mathrm{C})-\log (\mathrm{Q})$ slope, indicating enrichment, occurs when an increasing discharge additionally mobilizes solutes, (ii) a negative C-Q slope or dilution pattern 85 is commonly linked with source limitations and (iii) a neutral or chemostatic slope implies low variability in in-stream concentrations across a high range of discharges, a pattern observed for example for solutes derived from weathering bedrock (Ameli et al., 2017; Godsey et al., 2009). The potential information loss associated with linear and monotonic $\mathrm{NO}_{3}^{-} \log (\mathrm{C})$ $\log (\mathrm{Q})$ analysis was addressed by Moatar et al. (2017) and Minaudo et al. (2019) for more than 200 French catchments and by Diamond and Cohen (2018) for 44 rivers in Florida, USA. These studies identified distinct linear low-flow and high-flow $\mathrm{NO}_{3}^{-}$ $\log (\mathrm{C})-\log (\mathrm{Q})$ regression slopes for a majority of the cases. Moatar et al. (2017) found that stronger positive slopes under low flow conditions correlate positively with chlorophyll-a concentrations (associated with biological processes) and attributed this condition to biological $\mathrm{NO}_{3}^{-}$concentration mediation in the stream. This is consistent with the findings of Hall et al. (2009) and Hensley et al. (2014) among others that in-stream uptake is more efficient under low-flow than under high-flow. Furthermore, Wollheim et al. (2017) illustrates non-linear $\mathrm{NO}_{3}^{-} \mathrm{C}-\mathrm{Q}$ relationships conceptually for storm flow dynamics in a river network, showing high retention capacities in the headwater catchments that decrease under increasing flows, changing the slope of C-Q relationships from dilution to enrichment. Based on these studies we hypothesize that the magnitude (or 
efficiency) of in-stream $\mathrm{NO}_{3}^{-}$uptake is encoded within observed $\mathrm{C}-\mathrm{Q}$ relationships, and their analysis therefore can improve our understanding of in-stream uptake processes through providing an alternative to elaborate field and modelling work aimed at quantifying $\mathrm{NO}_{3}^{-}$removal in stream networks. Low frequency $\mathrm{NO}_{3}^{-}$observations are widely available (e.g. biweekly to monthly grab sampling, Ebeling et al., 2020 rev; Minaudo et al., 2019; Moatar et al., 2017) but if and how this data can be utilized to characterize catchment scale in-stream processing has yet to be investigated.

In this paper, it is postulated that network-scale uptake effects can be inferred from the non-linearity or bending of lowfrequency, multi-annual concentration $(C)$ and discharge $(\mathrm{Q})$ observations. To test this hypothesis, we apply a parsimonious river network model (similar to Bertuzzo et al., 2017; Helton et al., 2018; Helton et al., 2010; Mulholland et al., 2008) in 13 German catchments to explore the catchment scale transport and uptake processes that influence $\operatorname{downstream} \log (\mathrm{C})-\log (\mathrm{Q})$ patterns. The specific objectives are to (i) introduce Curvature as a robust metric to quantify bending of low frequency C-Q time series in the log-log space; (ii) explore the sensitivity of C-Q bending to hydrological and in-stream biogeochemical parameters (e.g. channel shape, water velocity and biological $\mathrm{NO}_{3}^{-}$uptake velocity); (iii) explore how $\mathrm{C}$-Q bending is linked to network scale in-stream uptake; (iv) provide guidelines if and on under what circumstances the C-Q bending can offer conclusive information on effective in-stream uptake. In this proof of concept exploratory study, we demonstrate how (existing) low-frequency monitoring data can be effectively utilized to quantify nitrate uptake in river networks and show how small scale uptake processes shape emerging patterns at catchment scales.

\section{Methods}

\subsection{Curvature}

The shape of C-Q relationships are often described as linear (Bieroza et al., 2018; Godsey et al., 2009; Musolff et al., 2017) or segmented linear (Meybeck and Moatar, 2012; Moatar et al., 2017; Marinos et al., 2020), implying a limit on the possible CQ shapes and setting assumptions such as 'fixed breaking points'. Here, we introduce the concept of Curvature to quantify rather than describe the shape of "broken-stick" C-Q relationships, without the assumption of a fixed form. In a strict geometrical sense the curvature $(-\infty ;+\infty)$ is the instantaneous rate of change of direction of a point that moves on a curve. A straight line for example has a curvature of zero and a large circle has a smaller curvature than a small circle (Pressley, 2010) (Fig. B1). Here, Curvature identifies the magnitude and direction of the $\log (\mathrm{C})-\log (\mathrm{Q})$ section with the largest instantaneous change. To calculate Curvature for an observed (noisy) C-Q relationship, a smoothed spline, $f$, is iteratively fitted with increasing degrees of freedom (df) to capture the general $\log (\mathrm{C})-\log (\mathrm{Q})$ shape accurately but avoid overfitting. Initially, df $=$

1253 and the $\log (\mathrm{Q})$ region of the largest instantaneous change is identified as $Q_{m} \pm 0.05$ with $Q_{m}=\arg \max \left|f^{\prime \prime}\right|$. Then, $\mathrm{df}$ is increased until, at $\mathrm{df}=\mathrm{i}$, the $\log (\mathrm{Q})$ corresponding to the largest instantaneous change is not within the initial $Q_{m}$ region 
anymore. Consequently, Curvature is calculated for a smoothed spline fit, $f$, with $\mathrm{df}=\mathrm{i}-1$ as $\left\{\begin{array}{l}\max _{\log Q} f^{\prime \prime} \text { if }\left|\max _{\log Q} f^{\prime \prime}\right| \geq\left|\min _{\log Q} f^{\prime \prime}\right| \\ \min _{\log Q} f^{\prime \prime} \text { if }\left|\max _{\log Q} f^{\prime \prime}\right|<\left|\min _{\log Q} f^{\prime \prime}\right|\end{array}\right.$. Curvature of a $\log (\mathrm{C})-\log (\mathrm{Q})$ relationship could be considered as a complementary metric to the slope of the linear regression model (Godsey et al., 2009) and could serve as an alternative for segmented linear regression fits (Meybeck and Moatar, 2012; Moatar et al., 2017; Marinos et al., 2020) (Fig. B2) as it quantifies bending.

We assume here that a multi-annual (6 to 15 years) low frequency (biweekly to monthly) C-Q relationship without temporal (significant) trends in a given station has one Curvature. To verify this assumption in a realistic setting, Curvature was computed for observed nitrate (C) and Q data (1995-2010) of French water quality stations with biweekly to monthly sampling frequencies (Dupas et al., 2019). Following the removal of $\mathrm{C}$ outliers (falling outside of $\mu \pm 3.5 \sigma$ in the log space, with $\mu$ and $\sigma$ representing the sample mean and standard deviation, respectively) 444 stations were selected that satisfy the following four criteria: (i) the station should have at least 70 coupled $\mathrm{C}$ and $\mathrm{Q}$ observations (total number of samples, n $\in$ [70;402]); (ii) a minimum of 6 years of data are represented; (iii) there is no bias in the intra annual distribution of the data (i.e. never less than $10 \%$ of the C-Q observations in one season); and (iv) the station $\mathrm{C}$ observations had no significant temporal trends (Mann

140 Kendall test, p-value > 0.05) (Ebeling et al., $2020 \mathrm{rev}$ ). We then assessed the robustness of Curvature to the low frequency CQ observations in a time series by selecting different subsamples of C-Q data from the entire available time series for a given station. More specifically, 100 random time series subsamples (each with a minimum length of 70) without replacement but with overlap were taken for each station, with the subsamples passing the four criteria above, and Curvature was calculated for each subsampled time series. On average, the subsamples represented nearly $80 \%$ of the complete time series for a station.

The estimated Curvature for the observed $\mathrm{NO}_{3}^{-} \log (\mathrm{C})-\log (\mathrm{Q})$ data ranges between -5.25 and 3.88 (median is -0.23 , Fig. B3) and $77 \%$ of the stations are characterized by Curvature $\leq 0$ or a linear or concave shape (similar to Moatar et al. 2017). The time series subsamples for each station generally had a small Curvature variability (Interquartile Range, IQR for a given station below 1) for $93 \%$ of the stations with some exceptions demonstrating a larger IQR up to 8. This indicates Curvature quantification for most low frequency C-Q time series is robust. The Spearman rank correlation $(\rho=0.53$, p-value $<2.2 \mathrm{e}-16)$ between the absolute observed Curvature and IQR for each station is significant and positive, implying that C-Q relationships with a higher absolute Curvature have a higher uncertainty when quantifying the C-Q bending. However, Curvature variability (IQR) in the subsamples for each station has no significant correlation with the number of data points available for one station. This implies that Curvature tends to be temporally robust when the C-Q data obeys the four above criteria so that the length of the low frequency time series length does not impact the estimated Curvature. Overall, the proposed Curvature metric quantifying the C-Q bending- is suitable to describe bending in multiannual, temporally stable $\log (\mathrm{C})-\log (\mathrm{Q})$ relationships. 


\subsection{Network Model}

In this work an explorative grid based (100 m x $100 \mathrm{~m}$ ) mass balance network model (comparable to Bertuzzo et al., 2017; Helton et al., 2018; Helton et al., 2010; Mulholland et al., 2008 and conceptually shown in Fig. B4) was used to simulate instream nitrate transport and biological removal on a daily basis. The model was developed in R (R Core Team, 2013).

\subsubsection{Stream network and hydrological properties}

Following Bertuzzo et al. (2017) and Helton et al. (2018), each river network node (i.e. grid cell) $i(1 \leq i \leq N)$ has a drainage area $A_{i}\left[\mathrm{~m}^{2}\right]$ that is calculated as the sum of the total upstream drainage area $\sum_{j} W_{j i} A_{j}\left[\mathrm{~m}^{2}\right]$ and the direct drainage area $a_{i}\left[\mathrm{~m}^{2}\right]$ (e.g. laterally contributing drainage area) to grid cell $i$ (Eq. (1)):

$A_{i}=\underbrace{\sum_{j} W_{j i} A_{j}}_{\text {Upstream Drainage Areas }}+\underbrace{a_{i}}_{\text {Direct Drainage Area }}$

where $W_{j i}[-]$ is an element in the connectivity matrix $W(\mathrm{~N} \times \mathrm{N})$ such that $W_{j i}=1$ if $j$ is directly neighboring and flowing into $i$ and $W_{j i}=0$ otherwise. $A_{j}\left[\mathrm{~m}^{2}\right]$ is the total drainage area to node $j$.

The total local discharge $Q_{i}$ at a given grid cell $i$ is proportional to the total drainage area at that grid cell, $A_{i},\left[\mathrm{~m}^{3} \mathrm{~s}^{-1}\right.$ ] (following Bergstrom et al., 2016 and Bertuzzo et al., 2017) (Eq. (2)), which in turn dictates the downstream hydraulic geometry relationships of river geomorphic parameters channel width, $w_{i}[\mathrm{~m}]$, and average channel depth, $d_{i}[\mathrm{~m}]$ (Leopold and Maddock, 1953) (Eq. (2.1) and Eq. (2.2)). The local velocity in a grid cell $v_{i}\left[\mathrm{~m} \mathrm{~s}^{-1}\right]$ is calculated according to Eq. (2.3) and the corresponding travel time, $T_{i}$ [days] is computed in Eq. (2.4):

$Q_{i}=Q_{t . s p} * A_{i}$

$175 w_{i}=K_{w} * Q_{i}^{a_{w}}$

$d_{i}=K_{d} * Q_{i}^{a_{d}}$

$v_{i}=\frac{Q_{i}}{w_{i} * d_{i}}$

$T_{i}=\frac{l_{i}}{v_{i}}$

where $Q_{t . s p}\left[\mathrm{~m}^{3} \mathrm{~s}^{-1}\right]$ is the specific discharge that is calculated as the ratio of the daily discharge at the outlet and the total number of catchment grid cells, consequently varying in time. Parameters $a_{w}[-]$ and $K_{w}[-]$ are the respective exponent and coefficient parameters in the river width-discharge relationship (Eq. (2.1)); while $a_{d}[-]$ and $K_{d}[-]$ compose the exponent and coefficient parameters of the depth-discharge relationship (Eq. (2.2)), respectively. The flow length through a grid cell $i, l_{i}$ [m], equals 100 or $100 \sqrt{2} \mathrm{~m}$ for horizontal/vertical or diagonal flow directions, respectively. The ratio of $a_{d}$ to $a_{w}$ corresponds to a parameter $r[-] \in \mathbb{R}^{+}$which prescribes the cross section geometry relation such that a triangular channel cross section is represented by $r=1$, a parabolic channel cross section by $r=2$ and channel cross sections with progressively flatter 
bottoms and steeper banks by increasing values of $r$ (Dingman, 2007). The width-discharge relation in Eq. (2.1) is conceptually illustrated in Fig. B5 for two sets of $a_{w}$ and $K_{w}$.

\subsubsection{Nitrate uptake}

Similar to Eq. (1) the incoming load, $L_{i n, i}\left[\mathrm{mg} \mathrm{s}^{-1}\right]$, to a river network grid cell $i$ is the sum of upstream load contributions

$L_{\text {in.up,i }}\left[\mathrm{mg} \mathrm{s}^{-1}\right]$ and direct land to stream loading $L_{i n . l s, i}\left[\mathrm{mg} \mathrm{s}^{-1}\right]$, given that $\mathrm{L}=\mathrm{CQ}$ (Eq. (3)). The contribution of direct land to stream loading concentration can be expressed as a power law (Musolff et al. 2017) with the exponent $b$ [-], the slope in the $\log (\mathrm{C})-\log (\mathrm{Q})$ relationship that is an indicator of the C-Q archetype (Godsey et al., 2009) and coefficient $c$ [-]. Following Jawitz and Mitchell (2011), the coefficient $c$ is calculated to yield the long-term mean in-stream input concentration $C_{m e a n}$ [mg L$\left.{ }^{-1}\right]\left(\right.$ Eq. (A1)). Additional $\mathrm{NO}_{3}^{-}$sources such as the load resulting from $\mathrm{NO}_{3}^{-}$release within the stream network as point sources are not considered here (similar to Bertuzzo et al., 2017; Wollheim et al., 2006), so that only concave or linear log(C)$\log (\mathrm{Q})$ patterns (Curvature $\leq 0$ ) can be simulated. Also, we do not consider other loading processes that may create bending at the catchment outlet (e.g., shifts in transport pathways and solute sources, Marinos et al. 2020).

$$
L_{\text {in }, i}=\underbrace{L_{\text {in.up }, i}}_{\text {Upstream Loads }}+\underbrace{L_{\text {in.ls, } i}}_{\text {Direct Land to stream Loading }}=\sum_{j} W_{j i} L_{j}+c *\left(Q_{t . s p} * a_{i}\right)^{b+1}
$$

The modelled in-stream $\mathrm{NO}_{3}^{-}$uptake follows first order removal kinetics (Alexander et al., 2000; Boyer et al., 2006; Ensign and Doyle, 2006), such that the outgoing load from grid cell $i, L_{i}\left[\mathrm{mg} \mathrm{s}^{-1}\right]$ is a fraction of the incoming load $L_{i n, i}($ Eq. $(4))$ and the absolute removed load $L_{r, i}\left[\mathrm{mg} \mathrm{s}^{-1}\right]$ can be described as (Eq. (5)) with the in-stream processing chiefly occurring at the sediments and biofilm at the benthic-pelagic interface (Wollheim et al., 2006). Here, $L_{r, i}$ is influenced by separate hydrological $\left(\frac{P_{i} * l_{i}}{Q_{i}}\right)$ and biological $\left(v_{f}\right)$ components (similar to Bertuzzo et al., 2017).

$L_{i}=L_{i n, i} * e^{-\frac{v_{f} * P_{i} * l_{i}}{Q_{i}}}$

$L_{r, i}=L_{i n, i}-L_{i}=L_{i n, i} *\left(1-e^{-\frac{v_{f} * P_{i} * l_{i}}{Q_{i}}}\right)$

where $P_{i}$ is the cross section wetted perimeter calculated from the Manning equation (using the bed slope $S_{i}$ and assuming a fixed roughness coefficient $\left.=0.03\left[\mathrm{~m} \mathrm{~m}^{-1}\right]\right)$ in open channels $($ Eq. $(\mathrm{A} 2))$. The uptake velocity parameter $v_{f}\left[\mathrm{~m} \mathrm{day}^{-1}\right]$ indicates the rivers total biological nutrient demand (areal uptake, $U\left[\mathrm{mg} \mathrm{m}^{-2}\right.$ day $\left.^{-1}\right]$ relative to in-stream concentration $C_{m e a n}\left[\mathrm{mg} \mathrm{L}^{-1}\right]$ ) with $v_{f}=k_{i} d_{i}$ and $k_{i}$ the first order removal constant (Ensign and Doyle, 2006; Wollheim et al., 2006). The parameter $v_{f}$ accounts for the processes altering the rate and form of downstream $\mathrm{NO}_{3}^{-}$delivery (Doyle, 2005) and is therefore not limited to denitrification only. We assume that $v_{f}$ is independent of the in-stream $\mathrm{NO}_{3}^{-}$concentration $C_{\text {mean }}$ (Pennino et al., 2014; O'Brien et al., 2007) such that the areal uptake rate $U=v_{f} * C_{\text {mean }}$ is tightly linked with $C_{m e a n}$ in a first order relationship. Others (e.g., Hensley et al., 2014; Mulholland et al., 2008; O’Brien et al., 2007) contrarily found explicit scaling relationships where $v_{f}$ decreases non-linearly for increasing $C_{\text {mean }}\left(10^{-4}-10^{1} \mathrm{mg} \mathrm{L}^{-1}\right)$ when considering distinct catchments. However, in 
215 Germany, the $\mathrm{NO}_{3}^{-}$concentration range across a range of catchments is small $\left(10^{-1}-10^{1} \mathrm{mg} \mathrm{L}^{-1}\right.$ according to Ebeling et al., 2020 rev) and rivers generally have minor longitudinal concentration variability (Hensley et al., 2014; Ensign and Doyle, 2006) which suggest independent definitions of $v_{f}$ and $C_{\text {mean }}$.

The Damköhler number $D a[-]$ is calculated as the ratio between transport $\left(\tau_{T}\right)$ and reaction $\left(\tau_{R}\right)$ timescales and is often used to characterize the relative importance of hydrological and biogeochemical processes in hydrological connected systems (Oldham et al., 2013; Kumar et al., 2020):

$D a=\frac{\tau_{T}}{\tau_{R}}=\frac{T T}{k^{-1}}$

where, $\tau_{T}$ represents as the effective travel time, $T T$ [days] or the exposure time scale under advective conditions. We estimated the catchment wide $T T$ as the spatiotemporal median of the sum of all downstream $T_{i}$ (Eq. (2.4)) for a grid cell in the network $\left(\sum_{i}^{0 u t} T_{i}\right.$ ) (similar to Bergstrom et al., 2016). Whereas $\tau_{R}$ represents the reactive time scale of biological processes. It is approximated as $k^{-1}$ [days ${ }^{-1}$ ] with the effective catchment wide $k$ estimated as the spatiotemporal median of the gridscale first order reaction constant $k_{i}=d_{i} / v_{f}$.

\subsection{Exploring Curvature with Monte Carlo Simulations}

Monte Carlo simulations are performed to explore how Curvature evolves from a range of model input parameter combinations 230 in a variety of catchments (Sect 2.3.1 below). These simulations utilize the same set of 11107 unique parameter combinations in each of study catchments that, during one model run, are each kept constant in time and uniform in space for simplicity. The unique parameter combinations are generated by Latin Hypercube sampling from uniform parameter ranges that are set according to literature values (Table 1). Some physical constraints were also imposed such that the channel geometry parameters $a_{w}$ and $a_{d}$ must obey continuity principles ( $a_{w}+a_{d}<1$ and $a_{w}>a_{d}$, following Leopold and Maddock, 1953).

235 The main simulation results are i) Curvature [-], deduced from simulated $\log (\mathrm{C})-\log (\mathrm{Q})$ relationships when minimum $80 \%$ of the $\mathrm{C}$ data is above the 'detection limit' of $0.002 \mathrm{mg} \mathrm{L}^{-1} \mathrm{NO}_{3}^{-}$; and ii) the network wide percentage load removed $L_{r . p e r c}$ [\%]. The latter is calculated as the median of the ratio between the daily absolute removed load and the daily absolute incoming load in the river network. While all outputs can be spatially and temporally explicit on a daily time step, Curvature is examined at the catchment outlet, integrating both spatial and temporal aspects. The Monte Carlo results are subsequently subjected to a

240 global sensitivity analysis with the PAWN method (Pianosi and Wagener; 2015) to elucidate influential model parameters. Furthermore a correlation analysis is conducted to explore how these influential parameters impact simulated Curvature. Finally, a Classification and Regression Tree algorithm (CART, Breiman et al., 1984) allowed us to visualize parameter interactions as detailed in Sect. 2.3.2 below.

245 Table 1: Network model parameter ranges for the Monte Carlo simulations.

\begin{tabular}{|lll|l|}
\hline Parameter Unit & Description & Range & References \\
\hline \hline
\end{tabular}


https://doi.org/10.5194/hess-2021-16

Preprint. Discussion started: 19 January 2021

(c) Author(s) 2021. CC BY 4.0 License.
Hydrology and

Earth System

Sciences

Discussions

\begin{tabular}{|clll|l|}
$v_{f}$ & {$\left[\mathrm{~m} \mathrm{day}^{-1}\right]$} & Uptake velocity & $10^{-4} ; 0.25$ & Marce and Armengol, 2009 \\
$b$ & {$[-]$} & Slope b lin. regress. $\log (\mathrm{C})-\log (\mathrm{Q})$ & $-1.5 ; 1.5$ & Musolff et al., 2017, Ebeling, 2020b \\
$C_{\text {mean }}$ & {$\left[\mathrm{mg} \mathrm{L}^{-1}\right]$} & Land to stream concentration & $10^{-4} ; 20$ & Ebeling, 2020b \\
$K_{w}$ & {$[-]$} & Coefficient width-Q function & $2.6 ; 20.2$ & Andreadis et al., 2013 \\
$a_{w}$ & {$[-]$} & Exponent width-Q function & $0.01 ; 0.54$ & Andreadis et al., 2013; Dingman, 2007 \\
$K_{d}$ & {$[-]$} & Coefficient depth-Q function & $0.12 ; 0.63$ & Andreadis et al., 2013 \\
$a_{d}$ & {$[-]$} & Exponent depth-Q functiom & $0.28 ; 0.667$ & Andreadis et al., 2013; Dingman, 2007 \\
\hline
\end{tabular}

\subsubsection{Catchment selection}

We applied the network model in 13 mesoscale catchments across Germany with varying sizes $\left(21-1450 \mathrm{~km}^{2}\right)$ and distinct geophysical settings as stream order, median discharge and catchment shape (quantified with the Horton form factor; Horton, 1945) (Table 2). The catchments were selected based on a database of water quality and catchment characteristics within Germany (Ebeling, 2020a). Three nested sub-catchments for the Selke as well as the Holtemme river system, both part of the Bode, a well-studied river system near the Harz Mountains in central Germany were included additionally (Fig. 1) (Ehrhardt et al., 2019; Rode et al., 2016; Winter et al., 2020; Mueller et al., 2018). All catchments had 10 years of uninterrupted daily Q data available between 1995 and 2010 (Musolff, 2020). The selected catchments were delineated in ArcMap (ESRI, 2011) from a 100 m x 100 m DEM (EEA, 2013; Ebeling et al., 2020 rev). A flow direction, flow accumulation and valley slope grid in the same resolution were established. The channel threshold drainage area for the network delineation was set to 150 grid cells $\left(1.5 \mathrm{~km}^{2}\right)$, which agreed well with the observed river network, resulting in a tree shaped river network with $\mathrm{N}$ grid cells or nodes.

260 Table 2: Catchment properties summary: Catchment Area, median Elevation, Slope and Topographical Wetness Index (TWI), maximum Strahler Stream Order, Horton form factor, Drainage Density, median discharge (Q) and the coefficient of variation of the discharge (CV Q).

\begin{tabular}{|c|c|c|c|c|c|c|c|c|c|c|c|}
\hline ID & River & $\begin{array}{l}\text { Area } \\
{\left[\mathrm{km}^{2}\right]}\end{array}$ & $\begin{array}{l}\text { Med. } \\
\text { elevation } \\
{[\mathrm{m}]}\end{array}$ & $\begin{array}{l}\text { Med. } \\
\text { slope } \\
{\left[{ }^{\circ}\right]}\end{array}$ & $\begin{array}{l}\text { Med. } \\
\text { TWI } \\
{[-]}\end{array}$ & $\begin{array}{l}\text { Stream } \\
\text { order } \\
{[-]}\end{array}$ & $\begin{array}{l}\text { Network } \\
\text { length } \\
{[\mathrm{km}]}\end{array}$ & $\begin{array}{l}\text { Horton } \\
\text { form factor } \\
{[-]}\end{array}$ & $\begin{array}{l}\text { Drainage } \\
\text { density } \\
{\left[\mathrm{km} \mathrm{km}^{-2}\right]}\end{array}$ & $\begin{array}{l}\text { Med. } \mathbf{Q} \\
{\left[m^{3} s^{-1}\right]}\end{array}$ & $\begin{array}{l}\mathbf{C V} \mathbf{Q} \\
{[-]}\end{array}$ \\
\hline 1 & Dahme & 20.9 & 105 & 1.50 & 10.08 & 2 & 11 & 0.67 & 0.52 & 0.02 & 1.13 \\
\hline 2 & Kraichbach & 422.5 & 164 & 2.84 & 9.45 & 4 & 228 & 0.23 & 0.54 & 0.85 & 0.47 \\
\hline 3 & Wertach & 658.1 & 833 & 4.30 & 9.17 & 4 & 391 & 0.14 & 0.59 & 10.60 & 0.96 \\
\hline 4 & Ammer & 713.7 & 858 & 8.34 & 8.80 & 4 & 416 & 0.29 & 0.58 & 14.98 & 0.84 \\
\hline 5 & Modau & 88.6 & 272 & 5.61 & 8.47 & 3 & 47 & 0.42 & 0.53 & 0.52 & 0.80 \\
\hline 6 & Leine & 993.2 & 276 & 4.40 & 8.95 & 4 & 525 & 0.45 & 0.53 & 6.22 & 0.85 \\
\hline 7 & Speyerbach & 142.0 & 187 & 3.58 & 9.84 & 3 & 104 & 0.17 & 0.73 & 0.66 & 0.64 \\
\hline 8 & Stör & 1452.2 & 25 & 0.90 & 10.63 & 5 & 905 & 0.46 & 0.62 & 14.10 & 0.76 \\
\hline 9 & Holtemme & 272.5 & 258 & 3.58 & 9.49 & 4 & 145 & 0.17 & 0.53 & 1.04 & 1.01 \\
\hline 10 & Selke Silberhütte & 94.5 & 456 & 4.02 & 8.72 & 3 & 49 & 0.27 & 0.51 & 0.56 & 1.34 \\
\hline
\end{tabular}


https://doi.org/10.5194/hess-2021-16

Preprint. Discussion started: 19 January 2021

(C) Author(s) 2021. CC BY 4.0 License.
Hydrology and

Earth System

Sciences

Discussions

\begin{tabular}{|c|c|c|c|c|c|c|c|c|c|c|c|}
\hline 11 & Selke Meisdorf & 282.1 & 342 & 3.94 & 9.03 & 3 & 160 & 0.35 & 0.57 & 0.70 & 1.34 \\
\hline 12 & Selke Hausneindorf & 460.1 & 263 & 2.90 & 9.60 & 4 & 256 & 0.37 & 0.56 & 0.65 & 1.50 \\
\hline 13 & Schleuse & 263.2 & 597 & 9.12 & 7.92 & 4 & 139 & 0.79 & 0.53 & 2.88 & 1.07 \\
\hline
\end{tabular}

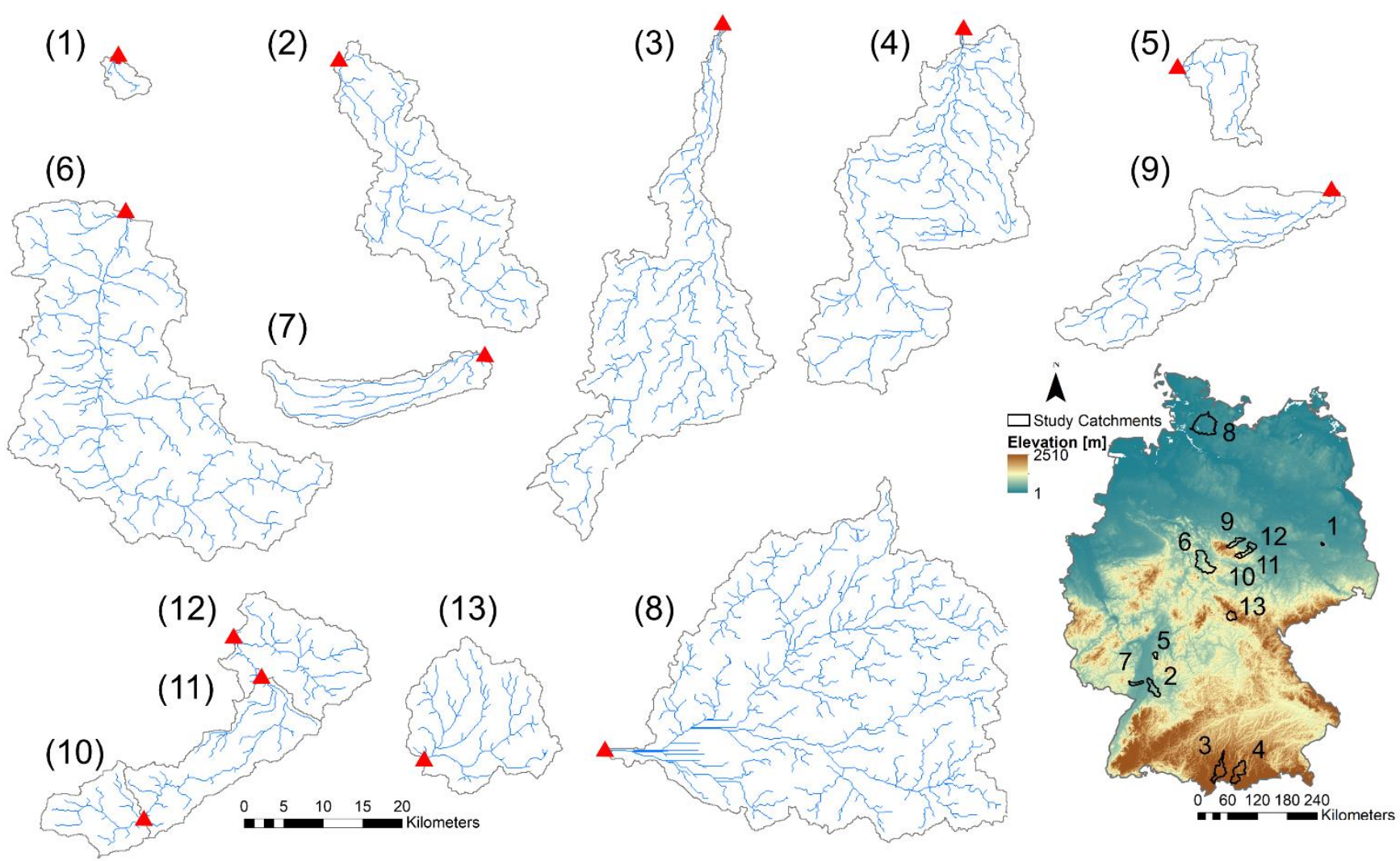

265 Figure 1: Germany DEM with the location and outline (shape) of selected catchments, along with their drainage networks (in blue) and outlet location (red triangle). See Table 2 for catchment ID's and properties.

To verify the model's ability to reproduce realistic concentration time series and Curvature, modeled and simulated data were compared in the Selke catchment (at Meisdorf gauging station; $282 \mathrm{~km}^{2}$, Table 2) where extensive field campaigns and modelling studies have been conducted related to in-stream processes (Rode et al., 2016; Dupas et al., 2017; Yang et al., 2019; Yang et al., 2018). This relatively homogeneous upstream part of the Selke consists of forest and cropland and is characterized by consistent export regimes (Winter et al., 2020). For an input parameter combination (Table C1) set to reasonable values for this catchment (Rode et al., 2016), the land to stream $\mathrm{NO}_{3}^{-}$inputs averaged $1.2 \mathrm{~kg} \mathrm{~N}$ day $^{-1} \mathrm{~km}^{-2}$ which is similar to the $1.9 \mathrm{~kg}$ $\mathrm{N}$ day ${ }^{-1} \mathrm{~km}^{-2}$ reported by Winter et al. (2020) for the Selke River (Meisdorf); and it is well within the general 0.001 to $100 \mathrm{~kg}$ $\mathrm{N}$ day ${ }^{-1} \mathrm{~km}^{-2}$ range established by Mulholland et al. (2008). Flow velocity had a spatiotemporal median value of $0.47 \mathrm{~m} \mathrm{~s}^{-1}$, which is also comparable with measured flow velocities (Risse-Buhl et al., 2017). Furthermore, daily discharge data, monthly 
nitrate concentrations (Winter et al., 2020) and integrated uptake measurements (Rode et al., 2016; Yang et al., 2019) were available for the Selke River (Meisdorf) between 2000 and 2012. Also, the spatially explicit nature of the network model was exploited here for the set input parameter combination (Table C1) to gain an insight into how the interplay of transport and uptake processes at every network grid cell can result in a curved C-Q pattern at the catchment outlet.

\subsubsection{PAWN sensitivity analysis and correlation analysis}

We performed a global sensitivity analysis (GSA) using the moment independent PAWN method (Pianosi and Wagener (2015). The method allowed for estimating the effect of the parameter inputs on the entire model output distribution and can be applied to rank the inputs and identify the uninfluential ones. The resulting PAWN sensitivity indices were estimated from generic input-output samples created with the numerical approximation strategy proposed by Pianosi and Wagener (2018). With this strategy, the range of variation of each input $x_{i}$ is partitioned into a number $n_{i}$ of equally probable 'conditioning' intervals $\left(I_{i, k}, k=1, \ldots, n_{i}\right)$, i.e. each interval contains the same number of data points. Given a scalar model output $y$ (here Curvature), the PAWN method compares the output conditional Cumulative Distribution Function $(\mathrm{CDF})\left(F_{y}(y)\right)$, computed by concurrently varying all the inputs, and the $n_{i}$ conditional CDFs for that input $\left(F_{y \mid x_{i}}\left(y \mid x_{i} \in I_{i, k}\right)\right)$. Each conditional CDF is obtained by varying all inputs within their entire range except for $x_{i}$, whose values are contained within one of the $n_{i}$ conditioning intervals. The Kolmogorov-Smirnov statistic (KS) is then calculated as the maximum vertical distance between the conditional and unconditional CDFs, while the PAWN sensitivity index $\left(S_{i}\right)$ for input $x_{i}$ aggregates the results over all conditional CDFs through a summary statistic as presented in Eq. (7):

$S_{i}=\underset{k=1 \ldots n_{i}}{\operatorname{stat}} K S\left(I_{i, k}\right)$

where $K S\left(I_{i, k}\right)=\max _{y}\left|F_{y}(y)-F_{y \mid x_{i}}\left(y \mid x_{i} \in I_{k, i}\right)\right|$

In this study, we applied Eq. (7) using $n_{i}=10$ conditioning intervals for each input parameter and the maximum KS value, $K S_{\text {max }}$, as summary statistics, which is an appropriate metric for screening non-influential input parameters. We estimated confidence intervals of the sensitivity indices using 15000 bootstrap resamples and checked the robustness of the results. The PAWN analysis was carried out using the Python version of the SAFE toolbox for global sensitivity analysis (Pianosi et al., 2015).

To explore the direction of change in the $\mathrm{C}-\mathrm{Q}$ bending at the catchment outlet resulting from variations in the model parameters and the catchment in-stream uptake, a Spearman rank correlation analysis was performed including all the simulated catchment responses and parameter combinations. These correlations were visualized in a correlation matrix using the 'corrplot' package in R (Wei and Simko, 2020).

\subsubsection{Identify parameter and model output interactions with classification tree}


Finally, we aim to determine if C-Q bending at the catchment outlet (specifically Curvature) informs about the network wide in-stream uptake. Thereto, a recursive modelling approach is proposed, using the Classification and Regression Trees algorithm (CART, Breiman et al., 1984) which allows for the identification of non-linear synergistic interactions among model parameters and output variables. This non-parametric method segregates classes for a response variable by progressively splitting selected predictor variables in a binary way. The resulting decision tree is simple and intuitive to interpret and can facilitate the fast characterization of river networks. The response variables include the effective catchment wide removal efficiency $L_{r}$, the Damköhler number $D a$ and the uptake velocity $v_{f}$, while the predictors are Curvature, the median network velocity $v$ and all of the model input parameters except for $v_{f}$ (Table 1). For each response variable, three classes are defined representing low, intermediate and high ranges found in the literature (Table 3) that each contain $5 \%$ of the simulation outputs (obtained by distributing the non-missing model simulations over 20 percentiles). The overall CART accuracy for each response variable is assessed by attributing $80 \%$ of the simulation outputs in the low, intermediate and high classes to a training sample and assigning the remaining $20 \%$ to a test sample. The training sample is then used to construct the classification tree while the test sample is needed to assess the prediction accuracy and calculating the performance statistics for each class. The CART analysis was performed using the 'caret' package in R with the Gini impurity measure as splitting criterion (Kuhn, 2020).

Table 3: Classes containing low, medium and high values for response variables $v_{f}$ (uptake velocity), $L_{r \text {.perc }}$ (percentage load 325 removed) and Da (Damköhler number) are used for the CART training and testing samples. Similar classes are obtained for model output Curvature. These classes stem from distributing the non-missing simulation data over 20 percentiles and selecting the percentiles corresponding to low, medium and high literature values with the respective percentile number (1-20) indicated in brackets. The training sample for constructing the CART model was then allocated $80 \%$ of this data and the test sample $20 \%$.

\begin{tabular}{|cl|lll|l|}
\hline Variable & Units & Low & Medium & High & References \\
\hline \hline$v_{f}$ & {$\left[m\right.$ day $\left.^{-1}\right]$} & $10^{-4}-0.01(1)$ & $0.10-0.11(10)$ & $0.23-0.24(20)$ & Birgand et al., 2007, Marce and Armengol, 2009 \\
$L_{r . p e r c}$ & {$[\%]$} & $3.8-5.2(7)$ & $28.7-35.1(15)$ & $63.0-75.3(19)$ & Birgand et al., 2007 \\
$D a$ & {$[-]$} & $0.17-0.25(3)$ & $0.88-1.02(10)$ & $3.25-4.19(18)$ & Oldham et al., 2013 \\
\hline Curvature & {$[-]$} & $-0.70 ;-0.51(3)$ & $-0.25 ;-0.22(9)$ & $-0.03 ;-0.01(18)$ & Dupas et al., 2019 \\
\hline
\end{tabular}

\section{Results and Discussion}

\subsection{Model validation in the Selke River (Meisdorf)}

To evaluate the network model performance in a realistic setting, we implemented the model with a fixed parameter combination (Table C1) in the Selke catchment and aimed to capture C-Q dynamics at the basin outlet. The simulated $\mathrm{NO}_{3}^{-}$ concentration time series for the Meisdorf station in Fig. 2a shows a seasonal pattern that follows the observation concentration

335 data reasonably well (Nash-Sutcliffe Efficiency; NSE $=0.50$, percent bias; pbias $=-0.4 \%$ ). This seasonality is also reflected in simulated daily percentage of load removed (the ratio between the daily total removed load and the daily total incoming 
https://doi.org/10.5194/hess-2021-16

Preprint. Discussion started: 19 January 2021

(c) Author(s) 2021. CC BY 4.0 License.

load in the river network); and ranges from almost $0 \%$ to $3.4 \%$ in this case, with the median $L_{r . p e r c}$ value equal to $0.41 \%$. The highest removal efficiencies are simulated in fall and summer and coincide with low simulated $\mathrm{NO}_{3}^{-}$concentrations at the catchment outlet. The observed nitrate concentrations generally show an enrichment export pattern in the $\log (\mathrm{C})-\log (\mathrm{Q})$ space $\left(b=0.40, R^{2}=0.56\right)$ and a Curvature of -0.35 which agrees well with the simulated Curvature of -0.28 (Fig. 2b). The observed low nitrate concentrations coincide with low discharges in fall and summer, while high concentrations occur mainly in winter when discharges are higher.
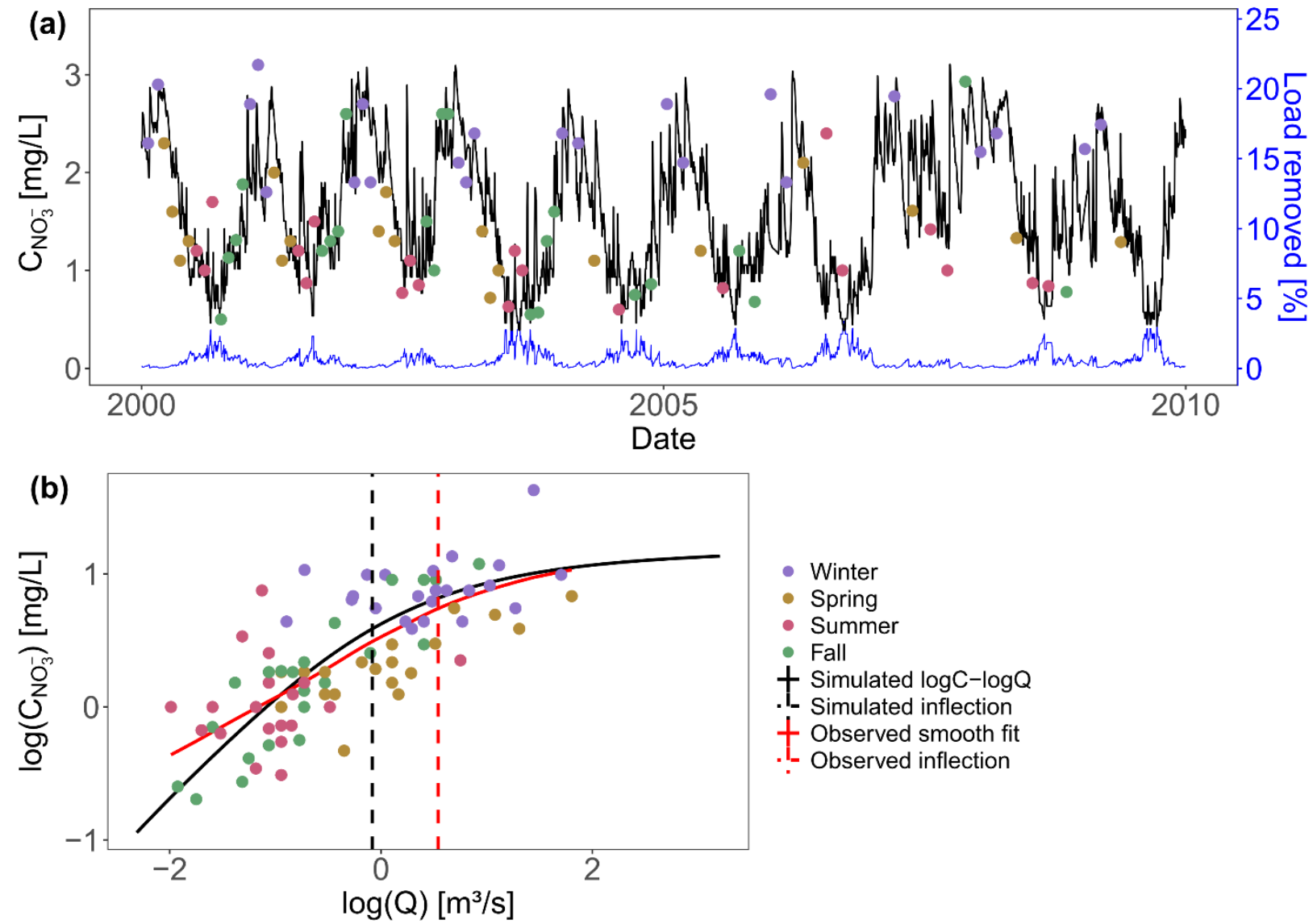

Figure 2: (a) Simulated and observed $\mathrm{NO}_{3}^{-}$concentrations at the Selke Meisdorf gauging station for a 10 year simulation period (2000-2010; NSE=0.50). One data point $\left(C \sim 5 \mathrm{mg} \mathrm{L}^{-1}\right)$ is not shown here. The simulated median percentage of load removed in the stream network (blue line) is given during the same time period. (b) The observed $\mathrm{NO}_{3}^{-}$concentrations and $\mathrm{Q}$ are log transformed and plotted together with the simulated C-Q data for 2000-2010. A smoothed spline is fitted to the observed and simulated C-Q data; and Curvatures of -0.35 and -0.28 are calculated at the respective discharges of $1.72 \mathrm{~m}^{3} \mathrm{~s}^{-1}$ and $0.92 \mathrm{~m}^{3} \mathrm{~s}^{-1}$, indicating the smoothed spline inflection points.

Within the Selke Meisdorf river network the simulated Curvature is largely contained within -1.12 to $-0.29\left(10^{\text {th }}\right.$ and $90^{\text {th }}$ quantiles respectively) for the given parameter combination (Table C1, Fig. 3). High Curvatures $(<-1.12)$ are found 
exclusively at grid cells with a low total drainage area $\left(A_{i}<9 \mathrm{~km}^{2}\right)$ and Curvature becomes stable with increasing drainage areas (inset Fig. 3, Fig. B5). The incoming ( $L_{\text {in.ls }}$ and $L_{\text {in.up }}$; Eq. (3)), removed ( $L_{r}$; Eq. (5)) and outgoing absolute load $\left(L_{i}\right.$; Eq. (4) with $L=C Q$ ) as function of $Q$ in the $\log -\log$ space are shown in Fig. 3 for three selected grid cells on the main river stem with low (C), intermediate (B) and high (A) drainage areas. The corresponding $\log (\mathrm{C})-\log (\mathrm{Q})$ relationship for the outgoing load $\left(L_{i}\right)$ at the outlet $(\mathrm{A})$ is presented in Fig. $2 \mathrm{~b}$. Note that Curvature is calculated from $\log (\mathrm{C})-\log (\mathrm{Q})$ relationships rather than $\log (\mathrm{L})-\log (\mathrm{Q})$. The loads in grid cell $\mathrm{A}, \mathrm{B}$ and $\mathrm{C}$ generally increase with discharge while the load removal efficiency decreases with discharge. The highest removal efficiencies are found in the headwater grid cell $\mathrm{C}$ (39\% for low discharge), followed by mid-stream grid cell B ( $3 \%$ for low discharge) and the outlet A ( $0.5 \%$ for low discharge). However, the total absolute load removed $\left(L_{r}\right.$, sum per year) is largest for the mid-stream grid cell B $\left(66.2 \mathrm{~kg} \mathrm{~N}\right.$ year $\left.^{-1}\right)$, followed by the headwater cell C $\left(25.6 \mathrm{~kg} \mathrm{~N}_{\text {year }}{ }^{-1}\right)$ and the outlet $\mathrm{A}\left(21.0 \mathrm{~kg} \mathrm{~N} \mathrm{~km}^{-2}\right.$ year $\left.{ }^{-1}\right)$. Finally, the total yearly incoming load $\left(L_{\text {in.ls }}+L_{\text {in.up }}\right)$ increases in the downstream direction from $658 \mathrm{~kg} \mathrm{~N}_{\text {year }}{ }^{-1}$ in the headwaters to $72716 \mathrm{~kg} \mathrm{~N}_{\text {year-1 }}{ }^{-1}$ at the basin outlet.
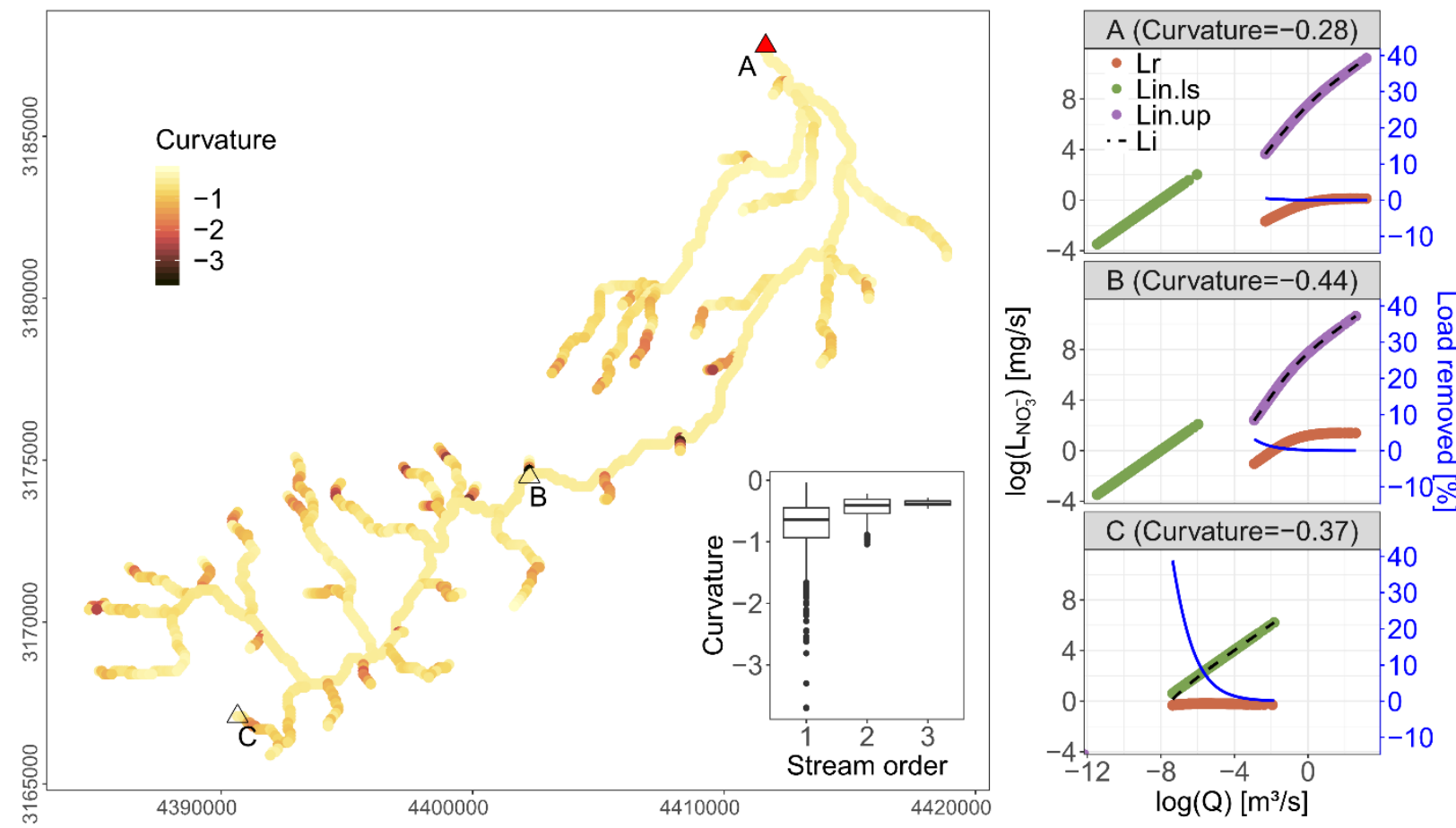

Figure 3: Spatial distribution of simulated Curvature in the Selke river network (Meisdorf) for a selected parameter set (see Table C1). Three representative grid cells covering low (A), intermediate (B) and high (C) total drainage areas show the incoming land to stream load as $L_{\text {in.ls }}$ (Eq. (3)), the incoming load from upstream as $L_{\text {in.up }}$ (Eq. (3)), the removed load as $L_{r}$ (Eq. (5)) and the outgoing load as $L_{\mathbf{i}}($ Eq. (4)) in the $\log (L)-\log (Q)$ space. The load removed as a percentage of the incoming load is presented on the secondary axis. The corresponding Curvatures for these grid cells are calculated from the $\log (C)-\log (Q)$ relationships rather than $\log (L)-\log (Q)$. 
With uniform, constant parameters the network model does not account for a spatiotemporal parameter variability. Nevertheless, it successfully (see NSE and pbias) reproduces the seasonality of the observed concentrations over the 20002010 period for the Selke Meisdorf catchment (Fig. 2a). For comparison, Yang et al. (2018) found a similar performance (NSE $=0.47$, pbias $=-3.35 \%$ ) when applying a fully distributed model with 16 calibrated parameters in this catchment between 1997 and 2009. The uptake velocity $v_{f}$ for our simulation was set to $0.098 \mathrm{~m} \mathrm{day}^{-1}$ to closely match the observed (assimilatory) uptake range of 0.009 to $0.103 \mathrm{~m} \mathrm{day}^{-1}$ for the Selke Meisdorf river network (Rode et al., 2016), the annual percentage load removed equals $4.7 \%$ which is within a comparable range reported in prior studies (Rode et al., (2016) and Yang et al., (2018) found annual means of 4.8 and $7.6 \%$ respectively). Yang et al. (2018) reported very high uptake efficiencies (up to $75 \%$ ) for summer seasons that were caused by low $\mathrm{NO}_{3}^{-}$concentrations $\left(0.21 \mathrm{mg} \mathrm{N} \mathrm{L}^{-1}\right)$ and load $(\mathrm{L}=\mathrm{CQ})$, which are not represented in our model simulation (the lowest simulated $\mathrm{NO}_{3}^{-}$concentration equaled $0.4 \mathrm{mg} \mathrm{N} \mathrm{L}^{-1}$ ). Additionally, due to the parsimonious structure of the proposed model, we did not account for the temporally changing effects of environmental factors like temperature and light availability that might (seasonally) influence uptake efficiencies in the river network. Nevertheless, these reported high low flow uptake efficiencies in summer are not a main contributor to the annual percentage load removed that is dominated by high flows, generally recorded during winter. Thus for the Monte Carlo simulations (Sect. 3.2 below) we calculated $L_{r . p e r c}$ as the median of the daily percentage load removed rather than the total removal efficiency for the entire simulated time period to better represent an effective long term network wide removal capacity.

The interplay of incoming, removed and outgoing load at each network grid cell shapes the $\log (\mathrm{L}) \operatorname{and} \log (\mathrm{C})-\log (\mathrm{Q})$ relationships; and thus the estimated Curvature at the catchment outlet (Fig. 3). Land to stream loading ( $\left.L_{\text {in.ls }}\right)$ that varies linearly with direct incoming discharge at a given grid cell (Eq. (3) with $\mathrm{L}=\mathrm{CQ}$ ) in the log space (Curvature $=0$ ) can lead to a bent outgoing $\log (C)-\log (\mathrm{Q})$ relationship where concentration or load $\left(\mathrm{L}_{\mathrm{i}}\right)$ varies non-linearly with discharge (Curvature $\neq$ 0 ). The onset of a bent $\log (\mathrm{C})-\log (\mathrm{Q})$ pattern $($ Curvature $=-0.37)$ is illustrated in the headwater grid cell $\mathrm{C}$ in Fig. 3 where $L_{i n . l s}$ is the only incoming load (upstream incoming load, $L_{\text {in.up }}$ equals 0 in this case). The absolute removed load is higher under increasing $\mathrm{Q}$ while the percentage load removed is lower, which explains observed C-Q patterns with higher $\log (\mathrm{C})$ $\log (\mathrm{Q})$ slopes for low flows than for high flows (Moatar et al., 2017; Wollheim et al., 2008; Doyle, 2005; Wollheim et al., 2017; Basu et al., 2011). This decreased $\mathrm{NO}_{3}^{-}$load removal efficiency at the basin outlet (spatial scale) or during events (temporal scale) can arise because stream morphology characteristics such as depth and water velocity, that correlate with varying discharge, constitute higher surface-to-volume ratios at the headwaters (generally low flows) than at the outlet (higher flows) (Peterson et al 2001; Hensley et al 2014). In the Selke Meisdorf case, uptake and land to stream loading at the downstream grid cells (B and A in Fig. 3) have a decreasing local impact on the outgoing load due to the large upstream contributions that increase in the downstream direction (see explicit scaling relationship for input flux in Bertuzzo et al., 2017). This is also explained by Wollheim et al. (2018) who suggests that the river network saturates as supply exceeds biological 'demand'. Dupas et al. (2017) on the other handshows how $\mathrm{NO}_{3}^{-}$uptake effects are decreasingly visible in $\mathrm{C}-\mathrm{Q}$ observations 
downstream and concentrations largely matched those estimated by a conservative mixing model. The saturation effect with

the accumulation of large load is reflected in the Curvature converging to a constant value when moving from upstream to downstream or from a lower order to a higher order river reach (Fig. 3, B6). This also corroborates the recent findings of Abbott et al. (2018) who found that the temporal variability (here reflected in the C-Q relationship) of nutrients is preserved moving downstream in a river network. Overall the Selke example shows that the network model can realistically reproduce the bending of observed $\mathrm{NO}_{3}^{-} \mathrm{C}-\mathrm{Q}$ relationships that evolve from the decreasing removal efficiency at higher discharges.

\subsection{Monte Carlo simulation results}

To elucidate how Curvature at the catchment outlet is shaped by in-stream transport and removal, a Monte Carlo simulation was run for the same 11107 model input parameter combinations (Table 1) in each of the 13 German catchments (Fig. 1). The overview of the model outputs for each study catchment in Table 4 shows that catchments 1,5 and 11 display the smallest $10^{\text {th }}$ quantile Curvature values of -1.61, -1.40 and -1.24 (highest bending) while the catchments 4 and 6 registered higher (lowest bending) and less variable Curvature (10 ${ }^{\text {th }}$ quantiles at -0.31 and -0.35$)$ (Fig. B7). Catchments 3,4 and 8 are characterized by high discharges (Table 2) at the catchment outlet and demonstrate low percentages of load removed, $L_{r . p e r c}\left(90^{\text {th }}\right.$ quantile at 29.8, 32.1 and $19.3 \%$ respectively). The highest $L_{r . p e r c}$ are found in catchments 1 and 10 (98.4 and $95.1 \%$ for the respective $90^{\text {th }}$ quantiles). The regression slope of the $\log (\mathrm{C})-\log (\mathrm{Q})$ relationship at the basin outlet, $b_{\text {out }}$, is positively skewed for all catchments compared to the slope $b$ of the land-to stream loading function that had no positive or negative preference (Table 1, Eq. (3)) with the most positive slopes found in catchment 5. The distribution of the concentrations at the catchment outlet, $C_{\text {out }}$, are generally similar across all catchments $\left(10^{\text {th }}\right.$ and $90^{\text {th }}$ percentiles within 0 to $\left.6.2 \mathrm{mg} \mathrm{L}^{-1}\right)$ and are significantly less variable than the land-to-stream incoming concentration (parameter $C_{\text {mean }}$ ) that varied from $10^{-4}$ to $20 \mathrm{mg} \mathrm{L}^{-1}$ across all the simulations (Table 1). The highest $C_{\text {out }}$ are found in the largest catchment 8. The median water velocity $v$ (Eq. (2.3)) is between 0.01 and $0.5 \mathrm{~m} \mathrm{~s}^{-1}$ for the $10^{\text {th }}$ and $90^{\text {th }}$ quantiles of all the study catchments. With the largest $v$ simulated for catchments 3 and 4 that also have the highest discharge. The median river network travel time, TT, for all simulations and catchments ranges from 0.1 to 4 days between their respective $10^{\text {th }}$ and $90^{\text {th }}$ quantiles and remarkably have no clear relationship with catchment properties as the total river network length (Table 2). Finally, the Damköhler number, $D a$ (Eq. (6)), is variable around 1 with the highest values, indicating reaction driven conditions, found for catchments 2 and 12 that respectively range from 0.6 to 10.3 and 0.7 to 10.8 for the $10^{\text {th }}$ and $90^{\text {th }}$ quantiles. The lowest $D a$ values are found for catchments 4 and $10\left(90^{\text {th }}\right.$ quantile <2) implying more transport driven conditions.

Table 4: $10^{\text {th }}$ and $90^{\text {th }}$ quantiles of model outputs Curvature, percentage load removed, $L_{r . p e r c}$, Damköhler number $D a$, regression slope of the $\log (C)-\log (Q)$ relationship at the basin outlet, $b_{\text {out }}$, the median concentration at the basin outlet, $C_{\text {out }}$, the median water network travel times, $\boldsymbol{T T}$, for each of the $\mathbf{1 3}$ German catchments. 


\begin{tabular}{|l|cc|cc|cc|cc|ccc|cc|cc|}
\hline Catch. & \multicolumn{2}{|c|}{ Curvature $[-]$} & \multicolumn{2}{c|}{$L_{r . p e r c}[\%]$} & \multicolumn{2}{c|}{$D a[-]$} & \multicolumn{2}{c|}{$b_{\text {out }}[-]$} & \multicolumn{2}{c|}{$C_{\text {out }}\left[\mathrm{mg} \mathrm{L}^{-1}\right]$} & \multicolumn{2}{c|}{$v\left[\mathrm{~m} \mathrm{~s}^{-1}\right]$} & \multicolumn{2}{c|}{$T T$ [days] } \\
ID & $10^{\text {th }}$ & $90^{\text {th }}$ & $10^{\text {th }}$ & $90^{\text {th }}$ & $10^{\text {th }}$ & $90^{\text {th }}$ & $10^{\text {th }}$ & $90^{\text {th }}$ & $10^{\text {th }}$ & $90^{\text {th }}$ & $10^{\text {th }}$ & $90^{\text {th }}$ & $10^{\text {th }}$ & $90^{\text {th }}$ \\
\hline \hline 1 & -1.61 & -0.01 & 2.6 & 98.4 & 0.3 & 6.4 & -0.65 & 2.22 & $<10^{-4}$ & 4.68 & 0.01 & 0.25 & 0.1 & 1.8 \\
2 & -1.04 & -0.01 & 0.9 & 78.5 & 0.6 & 10.3 & -0.42 & 2.31 & $<10^{-4}$ & 2.36 & 0.02 & 0.29 & 0.6 & 3.9 \\
3 & -0.43 & -0.02 & 0.2 & 29.8 & 0.2 & 2.8 & -0.54 & 1.96 & 0.01 & 5.27 & 0.07 & 0.48 & 0.5 & 3.3 \\
4 & -0.33 & -0.01 & 0.2 & 32.1 & 0.1 & 1.5 & -0.60 & 1.85 & 0.03 & 5.56 & 0.07 & 0.50 & 0.3 & 1.9 \\
5 & -1.40 & -0.01 & 1.3 & 85.1 & 0.1 & 2.0 & -0.49 & 2.43 & 0.01 & 3.76 & 0.04 & 0.38 & 0.2 & 1.5 \\
6 & -0.35 & -0.02 & 0.5 & 54.6 & 0.3 & 4.3 & -0.58 & 1.84 & 0.02 & 3.75 & 0.04 & 0.36 & 0.4 & 2.7 \\
7 & -0.44 & -0.01 & 0.8 & 72.6 & 0.2 & 3.6 & -0.52 & 2.09 & 0.01 & 4.4 & 0.04 & 0.38 & 0.4 & 2.8 \\
8 & -0.63 & -0.01 & 0.1 & 19.3 & 0.2 & 4.1 & -0.71 & 1.70 & 0.07 & 6.24 & 0.05 & 0.39 & 0.5 & 3.0 \\
9 & -0.68 & -0.01 & 0.8 & 70.4 & 0.3 & 5.3 & -0.53 & 1.99 & 0.01 & 3.43 & 0.04 & 0.35 & 0.5 & 3.1 \\
10 & -0.79 & -0.01 & 1.9 & 95.1 & 0.1 & 1.9 & -0.45 & 2.33 & 0.01 & 3.88 & 0.04 & 0.36 & 0.2 & 1.2 \\
11 & -1.21 & -0.01 & 1.6 & 85.6 & 0.5 & 7.4 & -0.48 & 2.35 & $<10^{-4}$ & 2.41 & 0.03 & 0.32 & 0.5 & 3.5 \\
12 & -0.97 & -0.01 & 1.5 & 83.2 & 0.7 & 10.8 & -0.49 & 2.07 & $<10^{-4}$ & 2.43 & 0.02 & 0.29 & 0.5 & 4.1 \\
13 & -0.46 & -0.01 & 1.3 & 72.9 & 0.1 & 1.5 & -0.72 & 1.69 & 0.05 & 4.35 & 0.05 & 0.42 & 0.2 & 1.4 \\
\hline
\end{tabular}

The Monte Carlo output in Table 4 shows reasonable results, as simulated Curvatures for all catchments and all parameter combinations (80\% of the values between -0.70 and -0.012 , Table 4 and Fig. B7) are comparable with the Curvatures from

$440 \mathrm{NO}_{3}^{-} \log (\mathrm{C})-\log (\mathrm{Q})$ relationships in the French catchments (80\% of the values between -0.41 and -0.067, Fig. B3) (Dupas et al., 2019). Note that simulated Curvature can only be smaller than and equal to zero as the model takes into consideration instream uptake (no release) and a uniform land to stream loading function. For the model output $L_{r . p e r c}$, a wide range of uptake efficiencies were captured from almost 0 to near to $100 \%$ (Mulholland et al., 2008) for some simulations and a median value of $14.4 \%$ across simulations. This simulated range however exceeds the proposed range by Birgand et al. (2007) of 10 to 70\% of $\mathrm{N}$ removal for agricultural drainage networks at annual time scales. High removal percentages (median over the simulated time period of daily percentage load removed in the network exceeding $95 \%$ ) are registered for $3.4 \%$ of all simulations while very limited load removal $\left(L_{\text {r.perc }}<5 \%\right)$ occurred for $32.1 \%$ of all the simulations. Other simulation outputs such as the effective velocity $v$ surprisingly rendered similar distributions across the catchments (Table 4 ) given that the median Q varied for almost three orders of magnitude at the basin outlet (Table 2). Their specific discharges (Sect. 2.2.1) were similar and by 450 taking the spatiotemporal median $v$ as an effective catchment value for each simulation the (more numerous) headwater grid cells were better represented than the grid cells close to the basin outlet. A similar effect is found for the range of the effective travel time TT. Generally these similar $v$ and TT distributions from model simulations between catchments align with the notion of Langbein and Leopold (1964) that drainage networks evolve naturally to transport water (and sediment) most efficiently such that an equilibrium between channel form and water and sediment load is imposed (Leopold and Maddock, 455 1953). Finally, also Damköhler numbers $D a$ exhibited realistic ranges, mostly distributed around 1 (Oldham et al., 2013 ; 
Ocampo et al., 2006), with $36.5 \%$ of the simulations $<0.8$ and $50.8 \%>1.2$ indicating that more simulations reaction driven than transport driven. Note that here $D a$ only takes into account in-stream transport and uptake.

As for the simulations, the same parameter input set is applied in each catchment, differences in model outputs between the catchments result from the combination of distinct transport and uptake processes in each river network. From Table 4 and Table 2 it is clear that differences in these three model outputs (i.e. Curvature, $L_{r . p e r c}$ and $D a$ ) between the catchments cannot be attributed to a single catchment property such as total network length or basin area. This could be due to a number of factors, for example Curvature has the highest variability between simulations in the smallest catchment 1 , compared to the other catchments, which could be due to variability in local loading and uptake patterns in the network driven by $\mathrm{Q}$ that are still visible at the catchment outlet. Following the simulated Selke Meisdorf example in Sect. 3.1 (Fig. 3, Fig. B6), it is shown that Curvature tends to converge to a constant value with increasing drainage areas (similar to Abbott et al., 2018 for nutrient concentrations, Dupas et al., 2017 for nutrient uptake and Bertuzzo et al., 2017 for DOC removal). Drainage area is however not the only catchment property influencing Curvature at the outlet. For example, catchment 6 is the second largest catchment (Table 2) and has the least bent (and least variable) $\log (\mathrm{C})-\log (\mathrm{Q})$ relationships. The network structure could possibly play a role here as the largest catchment 8 has some large tributaries near the basin outlet (Fig. 1), which could bypass removal and transport high load during events, introducing a more variable Curvature (Mineau et al., 2015; Helton et al., 2018). The percentage load removed, $L_{r . p e r c}$, is notably lower catchments with high Q - like 3, 4 and 8 (Table 4 ) which follows the narrative in Sect. 3.1 that uptake efficiency decreases with increasing Q because of increasing loads to the system (Wollheim et al., 2018; Mulholland et al., 2008) that also result in less efficient uptake within the reactive surface area (Peterson et al.,

2001; Hensley et al., 2014). The high $L_{\text {r.perc }}$ in small catchments 1 and 10 could then be attributed to their low Q, however why the small catchment 5 does not have similar uptake performance is less clear. Similarly, differences for the third output variable, $D a$, between the catchments are hard to pin down based on certain properties. Generally the model output variability between the catchments (as a result of different catchment properties) is minor compared to the output variability within the catchments (due to the effect of the chosen input parameter set). Nevertheless catchment properties as the drainage area and the network structure might influence observed Curvature in a way that cannot be disentangled with our approach and should be taken into consideration when interpreting $\log (\mathrm{C})-\log (\mathrm{Q})$ relationships for a given catchment.

\subsection{Curvature sensitivity analysis and model parameter correlation}

The PAWN sensitivity analysis clarifies the influence of each of the independent input parameters (Table 1), a variable derived 485 from these input parameters, the median water velocity $v$ (Eq. (2.3)), and an output variable, the Damköhler number, $D a$ (Eq. (6)) on Curvature. The sensitivity index $K S_{\max }$ in Fig. 4 and Table C2 shows that across all catchments Curvature is most sensitive to the exponents in the width-Q relation $a_{w}\left(K S_{\max }=0.62\right)$ and depth-Q relation $a_{d}\left(K S_{\max }=0.51\right)$ with little variability between the catchments ( $K S_{\max }$ has a low Coefficient of Variation, $\mathrm{CV}$, of 0.06 and 0.22 respectively). The slope 
of the linear loading function, $b$, is least important in shaping Curvature $\left(K S_{\max }=0.14\right)$ however a high variability of $K S_{\max }$ is observed $(\mathrm{CV}=0.76)$ that is caused by larger sensitivities for catchments 1 and $12\left(K S_{\max }\right.$ near 0.45$)$. Curvature is equally sensitive to $v_{f}$ and $C_{\text {mean }}\left(K S_{\max } 0.18\right.$ and 0.19$)$ but $v_{f}$ exhibits higher variability in $K S_{\text {max }}$ than $C_{\text {mean }}$ (CV 0.59 and 0.47 ), caused by catchments 12 and 1 . Furthermore, over all the catchments Curvature is sensitive to the median velocity $v$ and the Damköhler number $\mathrm{Da}$ ( $K S_{\max }$ equals 0.64 and 0.31 respectively, CV 0.26 and 0.38). When considering the catchments individually, basin 1 with smallest discharge has the highest median $K S_{\max }(0.59)$ across all input parameters, while catchment 4954 that has the highest discharge exhibits the lowest median $K S_{\max }(0.13)$. Additionally, Curvature is very sensitive to the velocity $v$ in catchment $1\left(K S_{\max }=0.95\right)$, while it is least sensitive to $v$ in catchment 4 . Overall, the results indicate that Curvature more sensitive to the model parameters in the low Q catchment 1 compared to the large Q catchment 4 , while the other catchments show no clear order in Curvature sensitivity according to their catchment properties. For example in nested catchments 10,11 and 12 (Fig. 1), the largest catchment 12 has the highest $K S_{\max }(0.50)$ and lowest CV (0.26) over all the input parameters, indicating that here Curvature is more sensitive to the input parameters here than in the smaller subcatchments 10 and 11 .

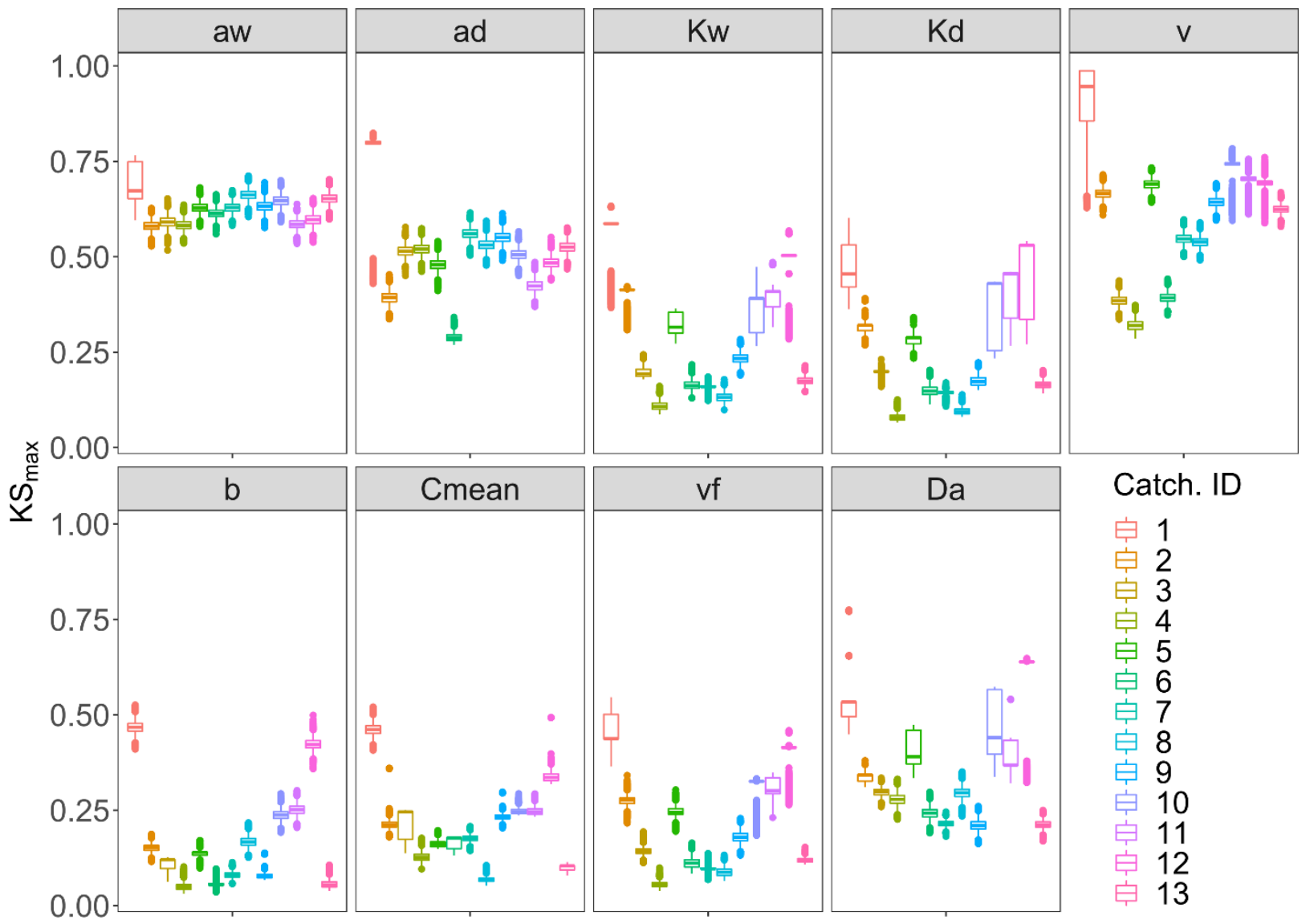


https://doi.org/10.5194/hess-2021-16

Preprint. Discussion started: 19 January 2021

(c) Author(s) 2021. CC BY 4.0 License.

Figure 4: The $K S_{\max }$ sensitivity index for each of the model input parameters and each of the 13 simulated catchments. The input parameters related to the channel geometry $\left(a_{d}, a_{w}, K_{d}\right.$ and $\left.K_{w}\right)$, land-to-stream loading $\left(b\right.$ and $\left.C_{m e a n}\right)$ and biogeochemistry $\left(v_{f}\right)$ are shown together with two variables derived from some of the input parameters: the median velocity $v$ and the Damköhler number Da. Each boxplot displays 15000 bootstrapped estimates of $K S_{\max }$ for each of the 13 simulated catchments.

In a next step the estimated Curvature across all simulations is correlated to the model input parameters as well as to output variables like the percentage load removed, $L_{\text {r.perc }}$, the $\log (\mathrm{C})-\log (\mathrm{Q})$ slope at the catchment outlet, $b_{\text {out }}$, the median concentration at the basin outlet $C_{\text {out }}$ and the uptake constant $k$ to identify the strength and direction of their relationship. The resulting Spearman correlation matrix (Fig. 5) reflects the PAWN sensitivity findings, with the highest Curvature correlation found with parameters $a_{w}(\rho=0.68)$ and $a_{d}(\rho=0.56)$ and input variable $v(\rho=0.57)$. Curvature is independent of $v_{f}(\rho=$ 0.04 ) but shows a negative correlation with $L_{\text {r.perc }}(\rho=-0.36$ ), suggesting that lower Curvature (higher bending) is related to a higher $L_{\text {r.perc }}$. Furthermore, Curvature is negatively correlated to the $\log (\mathrm{C})-\log (\mathrm{Q})$ regression slope at the catchment outlet $515 b_{\text {out }}(\rho=-0.28)$ such that higher bending coincides with more positive $b_{\text {out }}$. The variable $v$ is additionally strongly negatively correlated with $L_{r . p e r c}(\rho=-0.87)$ so high percentage load removed occurs at low velocities. $D a$ on the other hand is positively correlated to $L_{\text {r.perc }}(\rho=0.58)$ which indicates that higher $D a$ are occurring together with higher load removed. $D a$, thereby seems to be controlled more tightly by variation in $k^{-1}(\rho=-0.71)$ than by $T T(\rho=0.48)$. Finally $C_{\text {out }}$ is negatively correlated with $L_{r . p e r c}(\rho=-0.82)$ and $D a(\rho=-0.61)$. 


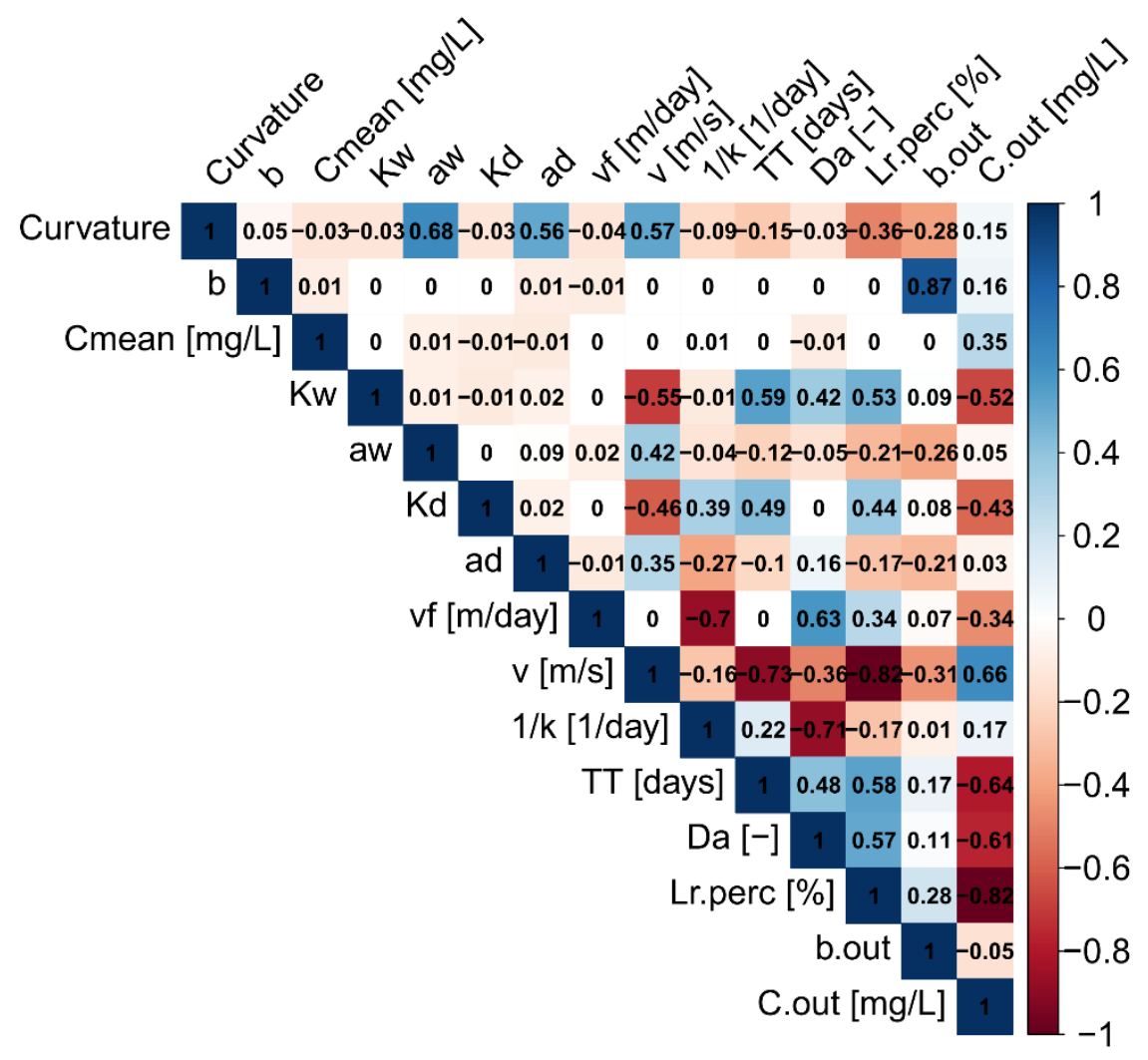

Figure 5: Correlation matrix for the model parameter inputs: channel depth and width exponents $a_{d}, a_{w}$ and coefficients $K_{d}, K_{w}$, slope of the land-to-stream loading, $b$, concentration of the land-to-stream load $C_{m e a n}$, uptake velocity $v_{f}$ and outputs: The bending of the $\log (C)-\log (Q)$ relationship at the catchment outlet, Curvature, effective stream velocity $v$, first order uptake constant $k$, travel time TT, Damköhler number $D a$, daily percentage load removed $L_{r \text { rperc }}$ and slope of the $\log (C)-\log (Q)$ relationship and median concentration at the outlet $b_{o u t}$ and $C_{o u t}$. The Spearman rank correlation coefficients $(\rho)$ are given for each combination.

The PAWN and correlation analysis results suggest the input parameters dictating the channel morphology $a_{w}$ and $a_{d}$ (Sect. 2.3), are controlling factors for the magnitude of the bending in $\log (\mathrm{C})-\log (\mathrm{Q})$ curves at the catchment outlet. Parameters $a_{w}$ and $a_{d}$ are the exponents in the respective width-Q and depth-Q relationships (Eq. (2.1) and (2.2)) and influence the response of the wetted perimeter $\left(P_{i}\right.$, Eq. (A2)) in a given reach in the network and thus the reactive surface area $\left(P_{i} * l_{i}\right)$ to changes in discharge. This is conceptually illustrated in Fig. B5. The correlation analysis outcomes imply that low Curvature (high bending) and low $a_{w}$ and $a_{d}$ occur together (Fig. 5). This is evident from the underlying model parameterizations, wherein the absolute load removed $L_{r, i}$ (Eq. (5)) is related with the width and depth exponents explicitly (Eq. (A3)) where $a_{w}$ and $a_{d}$ constitute the exponent of $\mathrm{Q}\left(1-a_{w}-a_{d}\right)$. When the latter term is large (small $a_{w}$ and $\left.a_{d}\right)$ there is a larger difference between 
the effect of low and high Q's on the local absolute removed load and which can lead to a higher Curvature (Sect. 3.1, Fig. B5). Network based modelling studies often set the width exponent $a_{w}$ to a value of 0.5 that was found to be representative for rivers globally (Bertuzzo et al., 2017; Rode et al., 2016; Wollheim et al., 2018). This a-priori fixed $a_{w}$ may, however, strongly affect the simulated C-Q dynamics at the basin outlet as is demonstrated here. Curvature finally shows the lowest sensitivity to the loading parameters $b$ and $C_{\text {mean }}$ that influence the incoming load to a grid cell (Eq. (3)) and thus impact the local absolute load removed $L_{r, i}$ (Eq. (5)) rather than the percentage removed load $L_{r \text {.perc }}$. This indicates that the contribution of local incoming load in the downstream direction has a limited impact on the $\log (\mathrm{C})-\log (\mathrm{Q})$ bending at the catchment outlet. Much like in the example shown for the Selke Meisdorf catchment in Sect. 3.1 where the locally contributing Q's are generally smaller (or equal for the headwaters) than the total Q in a given network reach so that the influence of the loading parameters $b$ and $C_{\text {mean }}$ on the total load decreases in more downstream reaches (Sect. 3.1, Fig. 3). Generally, for the entire river network, whether parameter $b$ has an enriching $(b>0)$, chemostatic $(b \sim 0)$ or diluting $(b<0)$ character or whether the land to stream loading concentration $C_{\text {mean }}$ is small or large has little influence on the observed bending at the outlet.

Although Curvature only has an intermediate sensitivity to the uptake velocity $v_{f}$ and they don't correlate well, $v_{f}$ is an important 'boundary condition' for $\log (\mathrm{C})-\log (\mathrm{Q})$ bending at the catchment outlet. No biological demand (low $v_{f}$ ) would mean that none of the incoming load would be removed from the river network. The outlet signal would in this case be solely driven by the discharge controlled transport processes and no bending would be observed (Curvature $=0$ ). Because $v_{f}$ is defined as a constant within one simulation that is independent of the local nutrient concentration (Sect. 2.2.2), the percentage of load removed in the network is mainly controlled by the varying hydrological conditions here represented by the effective network wide velocity $v\left(L_{\text {r.perc }}\right.$ and $\left.v, \rho=-0.82\right)$. This confirms that discharge and channel morphology are among the most important predictors of removal (Alexander et al., 2000; Seitzinger et al., 2002; Wollheim et al., 2006). The role of $v$ was further examined the context of restored and channelized streams (Kunz et al., 2017) and agree with our findings that decreased $v$ influences $\mathrm{N}$ cycling (Peterson et al., 2001). Nevertheless, by examining a range of $v_{f}$ in the Monte Carlo simulations, the positive correlation between the percentage load removed and the biogeochemical uptake velocity is clear $(\rho=0.32)$.

560 The PAWN and correlation analysis results show that Curvature is sensitive to the Damköhler number $D a\left(K S_{\max }=0.31\right.$ Fig. 4, Table C2) that has a high positive correlation with the percentage load removed $L_{r \text {.perc }}(\rho=0.58$; Fig. 5). This indicates that high $D a$ occur concurrently with more efficient removal and is in line with others (Ocampo et al., 2006) who found sometimes almost $100 \% \mathrm{NO}_{3}^{-}$removal in the riparian zones of an agricultural catchment with $\mathrm{Da}$ exceeding 2 . The transport timescale TT that makes up $D a\left(\rho=0.48\right.$; Fig. 5) together with the inverse of the first order uptake constant $k^{-1}(\rho=-0.71$; Eq. (6)) are examined for classes of low, median and high $D a$ (defined in Table 3) in Fig. 6a to disentangle which values of $k^{-1}$ and TT occur together and can constitute a certain $D a$ range (each class contains $5 \%$ of all simulations). It is shown here that low $D a$ are driven by both low TT and high, variable $k^{-1}$ implying a transport driven system with limited $\mathrm{NO}_{3}^{-}$removal 
(median $L_{r . p e r c}$ equals $2.4 \%$ in Fig. 6a for low $D a$ ). High $D a$, contrarily, have high $T T$ and low $k^{-1}$, fostering intermediate uptake percentages (median $L_{r . p e r c}=27.1 \%$ ). Although also $v_{f}$ clearly differentiates for classes of low, medium and high $D a$ in Fig. 6a, the corresponding Curvature values are similar in their range and mean. Nevertheless, this does not mean that $D a$ is not influencing Curvature at the basin outlet as there could be interactions with other inputs that are not captured here (which is supported by the PAWN findings, where $D a$ appears to be influential).

From the Curvature perspective (Fig. 6b) we identify model output ranges of $L_{r . p e r c}, D a$ and input variable $v_{f}$ that constitute low, median and high Curvature classes (Table 3). High Curvature ( -0.02) is thereby linked to low $L_{r . p e r c}$ (median $4.8 \%$ ), while low Curvature ( -0.60) is connected to higher and more variable $L_{r . p e r c}$ (median $33.6 \%$ ), generally indicating that more bent systems are more efficient in terms of removal and vice-versa. To explore some cases when this latter statement might not be true, we examine the input parameter ranges where high bending simulations (Curvature $<-0.51,13.1 \%$ of all simulations) occur concurrently with low percentage removal $\left(L_{r . p e r c}<5.2 \%, 0.9 \%\right.$ of all simulations) on the one hand and high percentage removal $\left(L_{r . p e r c}>63.0 \%, 4.9 \%\right.$ of all simulations) on the other hand in Fig. B8a. Here, it is seen that high bending, low uptake cases mainly occur for simulations with a high effective velocity $v$ (driven by lower values for the channel shape parameters $K_{w}, K_{d}, a_{w}$ and $a_{d}$ ). As discussed before, low $a_{w}$ and $a_{d}$ are correlated with a high bending (low Curvature) and Curvature is most sensitive to these parameters. However, we show here that these low $a_{w}$ and $a_{d}$ do not lead to a more efficient $\mathrm{NO}_{3}^{-}$uptake if the other channel shape parameters cause relatively high velocities (median $v>0.1 \mathrm{~m} \mathrm{~s}^{-1}$ ), throughout the network. Although the latter case is shown to be true for a minor percentage of all simulations ( $0.9 \%)$, it still explains why low Curvature (high bending) can be connected to a wider range of $L_{r . p e r c}$. A similar analysis in Fig. B8b for low bending (Curvature $>-0.03)$ shows that concurrent high removal simulations $\left(L_{r . p e r c}>63.0 \%\right)$ are even rarer $(0.1 \%$ of all simulations) compared to concurrent low removal $\left(L_{\text {r.perc }}>5.2 \% ; 7.4 \%\right.$ of all simulations). Deviations from the expected 'high Curvature - low $L_{\text {r.perc }}$ pattern are also here driven by (very low) $v$. In this case however, $a_{w}$ and $a_{d}$ are generally high in both cases (leading to high Curvature) and the different $v$ stem from coefficients $K_{w}$ and $K_{d}$ that are higher in high removal simulations. Finally, Fig. 6d illustrates that low medium and high uptake velocities $v_{f}$ lead to distinct $D a$ and $L_{r . p e r c}$ but do not show up in the bent signal at the catchment outlet. 


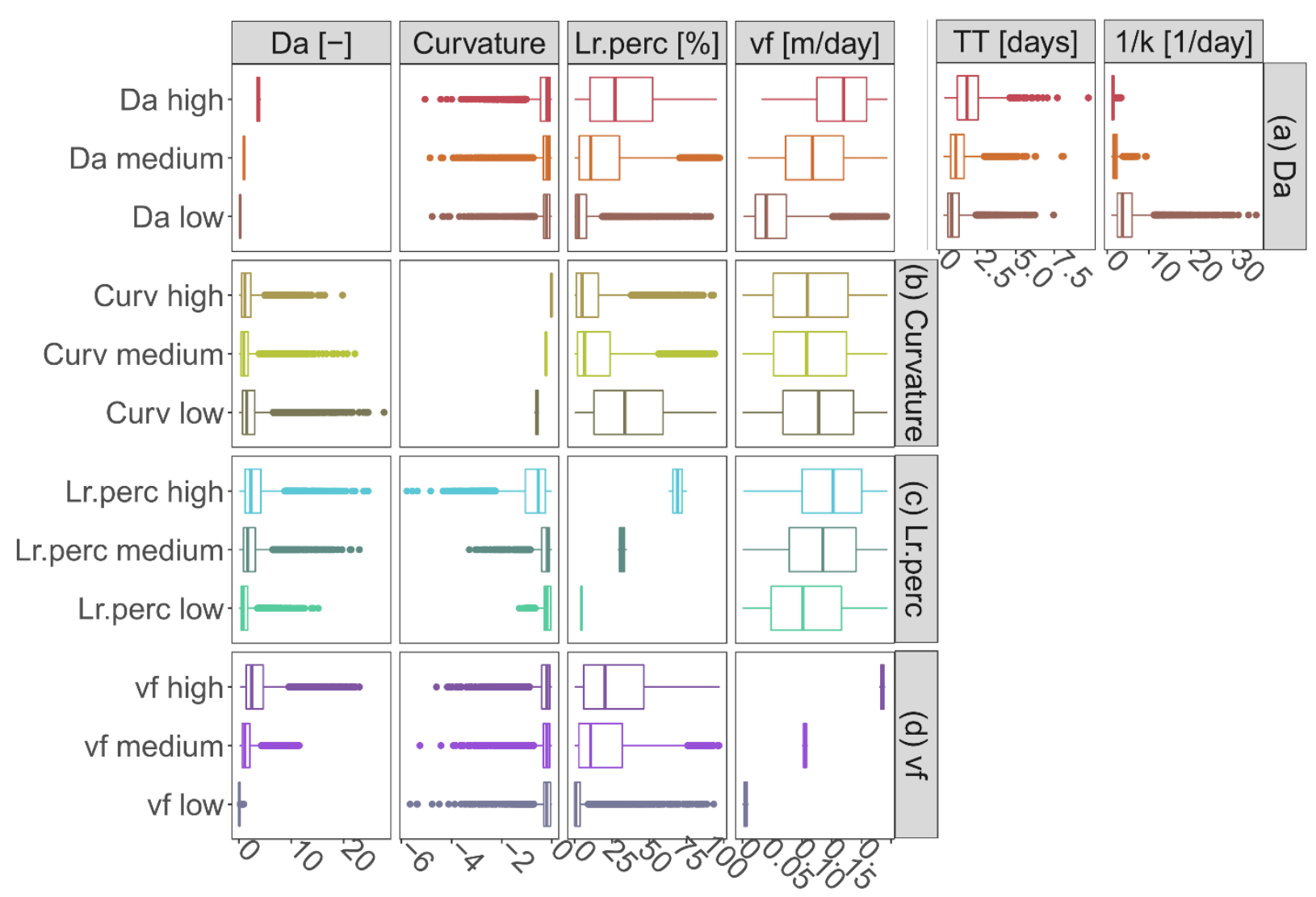

Figure 6: The corresponding simulated ranges for high, median and low values (Table 3) of the main simulation outputs: (a) Damköhler number Da, (b) Curvature, (c) Percentage load removed $L_{r . p e r c}$ and (d) uptake velocity $v_{f}$ are shown for the same variables (in the columns). The median travel time, $T T$, and the inverse of the first order uptake constant, $k^{-1}$ are given additionally for low medium and high $\mathrm{Da}$.

\subsection{Predicting in-stream processing with Curvature}

600 To determine if observed C-Q bending at the catchment outlet (here Curvature) can be utilized to quantify in-stream uptake in the upstream river network and to visualize model parameter interactions, a classification tree was established for low, medium and high values (Table 3, Fig. 6) of the response variables $L_{r . p e r c}, D a$ and $v_{f}$ (Fig. 7a, b and c respectively). The prediction accuracy metrics in Table $\mathrm{C} 3$ and the probability histograms in Fig. 7 show that $L_{r . p e r c}$ can be predicted relatively well (overall accuracy of 0.66) compared to the other response variables $D a$ (accuracy 0.51) and $v_{f}$ (accuracy 0.40). The fitted CART models all perform significantly better than a random allocation of simulation results to each class for each response variable (Accuracy > No Information Rate, p-value $<2.2 \mathrm{e}-16$ ). While the classes for $L_{r . p e r c}$ and $v_{f}$ are partitioned using only the network effective velocity $v$ and Curvature, predicting $D a$ in our case requires information on the channel geomorphology parameters the width coefficient $K_{w}$ and the depth exponent $a_{d}$. The histograms for each of the response variables in Fig. 7 
https://doi.org/10.5194/hess-2021-16

Preprint. Discussion started: 19 January 2021

(c) Author(s) 2021. CC BY 4.0 License.

indicate the probability of a test sample to be of a certain class when following the partition rules in the respective decision tree. For example, for $L_{r . p e r c}$ the probability that the daily percentage load removed is small (around $8 \%$ ) exceeds 0.95 when the effective velocity $v$ in the catchment is larger than $0.22 \mathrm{~m} \mathrm{~s}^{-1}$; while the probability that $L_{r . p e r c}$ is high (around $70 \%$ ) in this case is close to 0 (Fig. 7a). For $v_{f}$ the lowermost (1) and highest (20) classes are predicted most accurately $(0.58$ and 0.56 respectively, Table C3) and indicate that when the velocity is not very small and Curvature is smaller than - 0.51 (more bent), $v_{f}$ is most likely high (probability 0.59). For $D a$, the lower and higher classes can be predicted most accurately (0.69 and 0.68

615 respectively), for example, $D a$ is small with a probability of 0.58 when $K_{w}$ is relatively low $(<6.8)$. When on the other hand $K_{w}$ exceeds 6.8 and $a_{d}$ is larger than 0.4 or when $a_{d}$ is smaller than 0.4 but Curvature is smaller than -0.45 and $v$ is very small $\left(<0.04 \mathrm{~m} \mathrm{~s}^{-1}\right)$ it is most likely that $D a$ is large.

(a) Lr

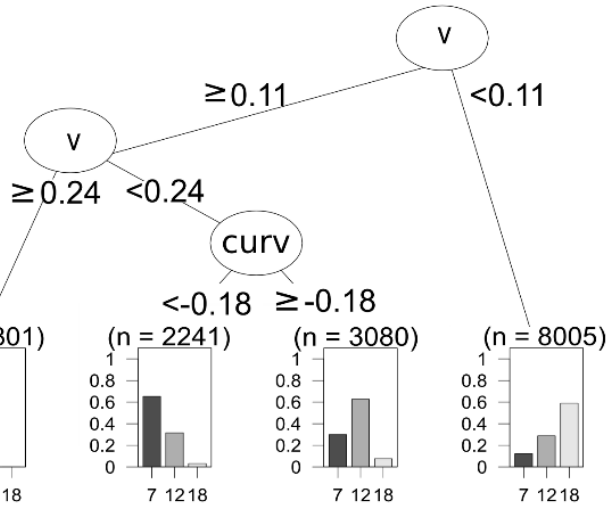

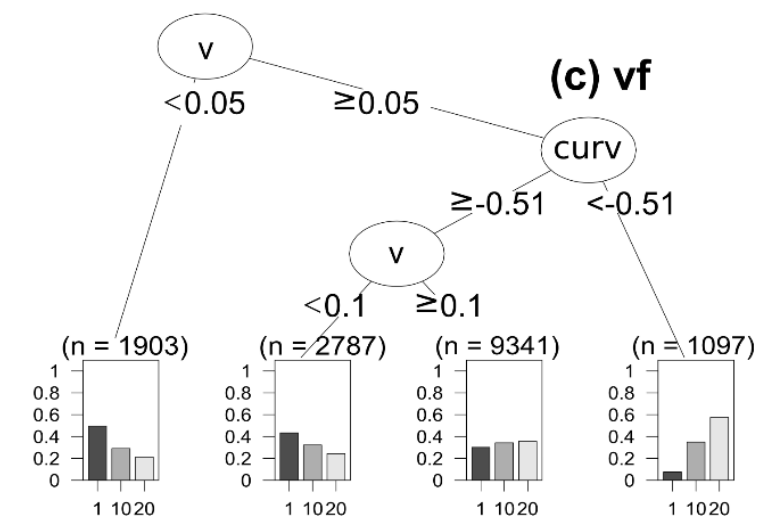

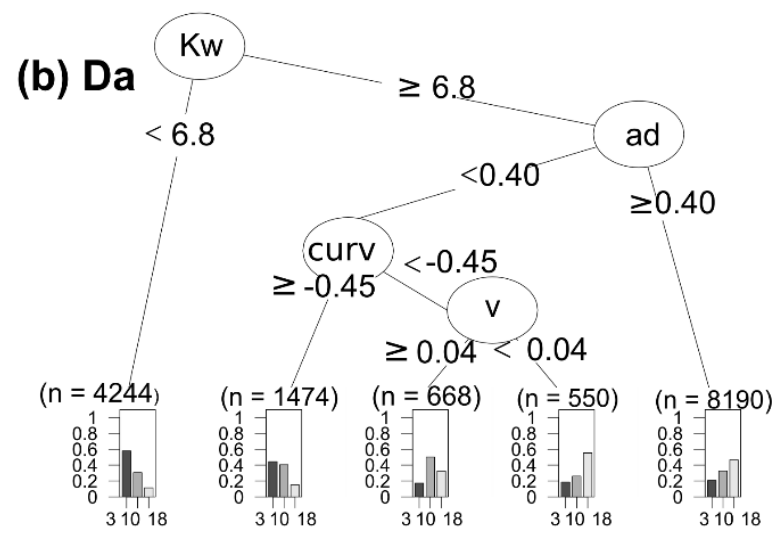

620 Figure 7: CART decision tree for the response variables $L_{r . p e r c}($ accuracy $=0.66), D a($ accuracy $=0.51)$ and $v_{f}($ accuracy $=0.40)$. The classes of each response variable are defined in Table 3 and the prediction metrics for these classes are stated in Table C3. The histograms illustrate the probability of a test sample to be from a certain class when following the binary splits of the decision tree. 
These findings demonstrate that $\log (\mathrm{C})-\log (\mathrm{Q})$ bending at the catchment outlet, together with the median velocity and the daily percentage load removed $L_{r . p e r c}$, the Damköhler number $D a$ and to a certain extent the uptake velocity $v_{f}$. The velocity may be concluded from the channel shape, discharge (Eq. (2.3)) and the topography with the channel shape parameters sometimes available from rating curve information or detectable from high resolution satellite pictures. The CART models could help obtain an initial probability of $\mathrm{NO}_{3}^{-}$removal efficiency in a river network, especially in a context where network wide uptake measurements are scarce (Wollheim et al., 2017; Hensley et al., 2014) and physical, fully distributed models are not always feasible to apply (Boyer et al., 2006; Klemes, 1986). Although the CART models are developed using 'only' the 13 German catchments included in the Monte Carlo analysis, in Sect. 3.2 and Table 4 we shown that the output variability between the catchments (as a result of different catchment properties) is minor compared to the output variability within the catchments (due to the effect of the input parameter set). Nevertheless, the prediction performance of these CART models might be influenced in unknown ways when applied to catchments with dissimilar catchment sizes, network structures or hydrological regimes.

\section{Conclusions}

In this study, we explore how $\mathrm{NO}_{3}^{-} \log (\mathrm{C})-\log (\mathrm{Q})$ relationships, observed at a basin outlet, can display bending as a result of network scale in-stream uptake processes. We established a parsimonious grid based river network model for 13 distinct German catchments and investigated the influence of in-stream loading, transport and uptake parameters on the bending of $\log (\mathrm{C})-\log (\mathrm{Q})$ relationships. Based on our exploratory analysis we conclude that:

- Noisy, multi-annual and low frequency $\mathrm{NO}_{3}^{-} \log (\mathrm{C})-\log (\mathrm{Q})$ relationships at a basin outlet can be described as bent and this bending can be robustly quantified with the new Curvature metric. Curvature tends to converge with increasing drainages areas and is temporally stable on multi-annual time scales.

- A bent $\log (\mathrm{C})-\log (\mathrm{Q})$ relationship (Curvature < $)$ at the basin outlet can arise from $\log -\log$ linear land to stream C$\mathrm{Q}$ relationships and uptake within the river network. This supports the hypothesis that more positive slopes under low flow (bended $\log (\mathrm{C})-\log (\mathrm{Q})$ curves) are linked to biological $\mathrm{NO}_{3}^{-}$concentration mediation in the stream (Moatar et al., 2017); and connects Curvature (as a quantitative measure) to observations of increased removal efficiency under low flows (Wollheim et al., 2017).

- The bending at the catchment outlet is primarily shaped by the channel geomorphological parameters, $a_{w}$ and $a_{d}$ (exponents in the respective stream width and depth to discharge relationships; with Curvature sensitivity indices $K S_{\max }$ equal to 0.62 and 0.51 ; and Spearman correlation coefficient, $\rho$, equaling 0.68 and 0.56 respectively) and less by the uptake velocity $v_{f}\left(K S_{\max }=0.18, \rho=-0.04\right)$, given that $v_{f}$ differs from zero. In that case Curvature would equal zero and the $\log (\mathrm{C})-\log (\mathrm{Q})$ relationship would be solely shaped by the accumulation of upstream load. Thus, the change of reactive channel bed area with discharge (mediated by $a_{w}$ and $a_{d}$ ) has a greater influence on the bending 
at the outlet than the biological removal capacity (here $v_{f}$ ). Additionally we demonstrate that an a-priori fixed $a_{w}$ might strongly affect the simulated C-Q dynamics at the basin outlet.

- Curvature at the basin outlet can be linked to the network-wide removal efficiency $L_{r . p e r c}(\rho=-0.36)$, indicating that systems with more bending in their $\log (\mathrm{C})-\log \mathrm{Q})$-relationship are more efficient in terms of removal and vice-versa. It is, however, clear that also cases with high bending (Curvature <-0.51) and low removal $\left(L_{\text {r.perc }}<5.2 \%, 0.9 \%\right.$ of all simulations) or low bending (Curvature $>-0.03)$ with high removal $\left(L_{r . p e r c}>63.0 \%, 0.1 \%\right.$ of all simulations) exist that are imposed by respective higher and lower network wide median velocities. This shows how the velocity, $v$, (calculated from the channel shape parameters $a_{w}, a_{d}, K_{w}$ and $K_{d}$ ) may mediate the connection between $L_{r . p e r c}$ and Curvature and stresses that $v$ should be considered when interpreting $\log (\mathrm{C})-\log (\mathrm{Q})$ bending.

- Simple classification trees - like CART - can be useful for predicting low, median and high classes of response variables $L_{r \text {.perc }}$, the Damköhler number $D a$ and $v_{f}$. They provide useful insights on how catchments with low frequency concentration and discharge time series (that are generally available) can reveal information on the upstream river network uptake performance.

670 To evaluate the generality of the results presented here, Curvature should be calculated for $\mathrm{NO}_{3}^{-}$concentration observations of a larger range of catchments and linked to the respective catchment properties. Properties such as light and stream ecological state can serve as proxies for uptake performance and for example topographic gradient can be a proxy for network transport velocity. Such a data-driven exploration would further elucidate the linkages between nutrient uptake efficiency and lowfrequency $\mathrm{C}$ and $\mathrm{Q}$ observations. 
https://doi.org/10.5194/hess-2021-16

Preprint. Discussion started: 19 January 2021

(c) Author(s) 2021. CC BY 4.0 License.

\section{Appendix A}

c calculation (Jawitz and Mitchell, 2011)

$c=e^{\mu_{c}-b * \mu_{q}}$

680 With

$\mu_{q}=\operatorname{mean}\left(\log Q_{t . s p} * a_{i}\right)$

$\mu_{c}=\log$ meanc $-\frac{\sigma_{c}^{2}}{2}$

$\sigma_{c}=\sqrt{b^{2} * \sigma_{q}^{2}}$

$\sigma_{q}=\sqrt{\operatorname{var}\left(\log Q_{t . s p} * a_{i}\right)}$

685

Stream channel wetted perimeter $P_{i}[L]$, where $A$ is the cross-sectional area $\left[L^{2}\right], R_{H}[L]$ is the hydraulic radius and $w_{i}[L], d_{i}$ $[\mathrm{L}]$ and $\mathrm{v}_{\mathrm{i}}[\mathrm{L} / \mathrm{T}]$ are the local stream width, average depth and velocity respectively. $S_{\mathrm{i}}[\mathrm{L} / \mathrm{L}]$ is the stream bed slope and $n[-]$ is the Manning roughness coefficient that is equal to 0.03 for all simulations.

$P_{i}=\frac{A}{R_{H}}=\frac{w_{i} * d_{i} * S^{\frac{3}{4}}}{\left(v_{i} * n\right)^{\frac{3}{2}}}$

690

The load removed in a grid cell (Eq. (5)) with the width and depth exponents, $a_{w}$ and $a_{d}$, stated explicitly.

$L_{r, i}=L_{i n, i} *\left(1-e^{-\frac{v_{v^{*}\left(K_{W^{*}} K_{d}\right)^{\frac{5}{2}} * S^{\frac{3}{4}} * n^{\frac{3}{2}}}}{Q_{i}{ }^{1-a_{W^{-}} a}}}\right)$

The velocity in a grid cell (Eq. (2.3)) with the width and depth exponents, $a_{w}$ and $a_{d}$, stated explicitly.

$695 v_{i}=\frac{Q^{1-a_{w}-a_{d}}}{K_{w^{*} K_{d}}}$ 
https://doi.org/10.5194/hess-2021-16

\section{Appendix B}

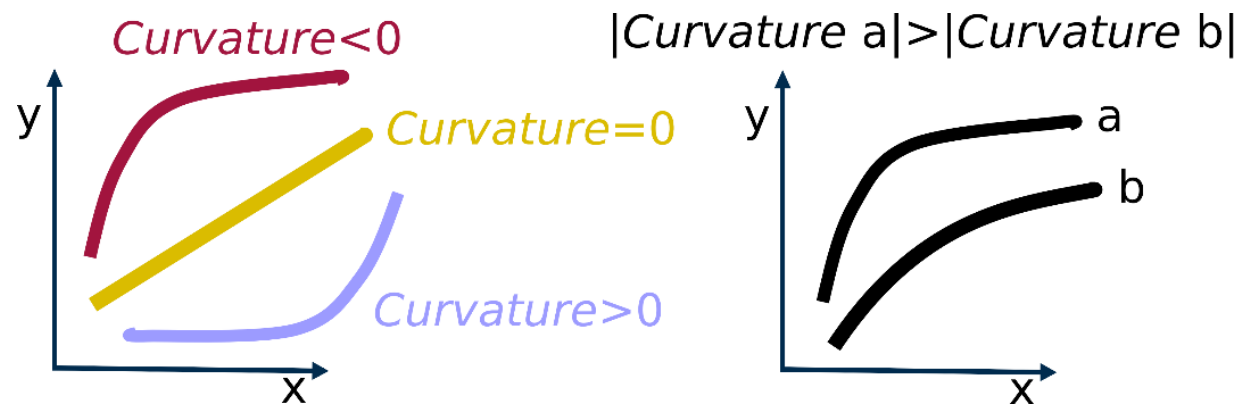

700 Figure B1: Conceptual figure explaining Curvature. Curvature is calculated as the largest instantaneous rate of change of direction of a point that moves on a curve. When Curvature $<0$ the curve is concave, for Curvature $>0$ the curve is convex.

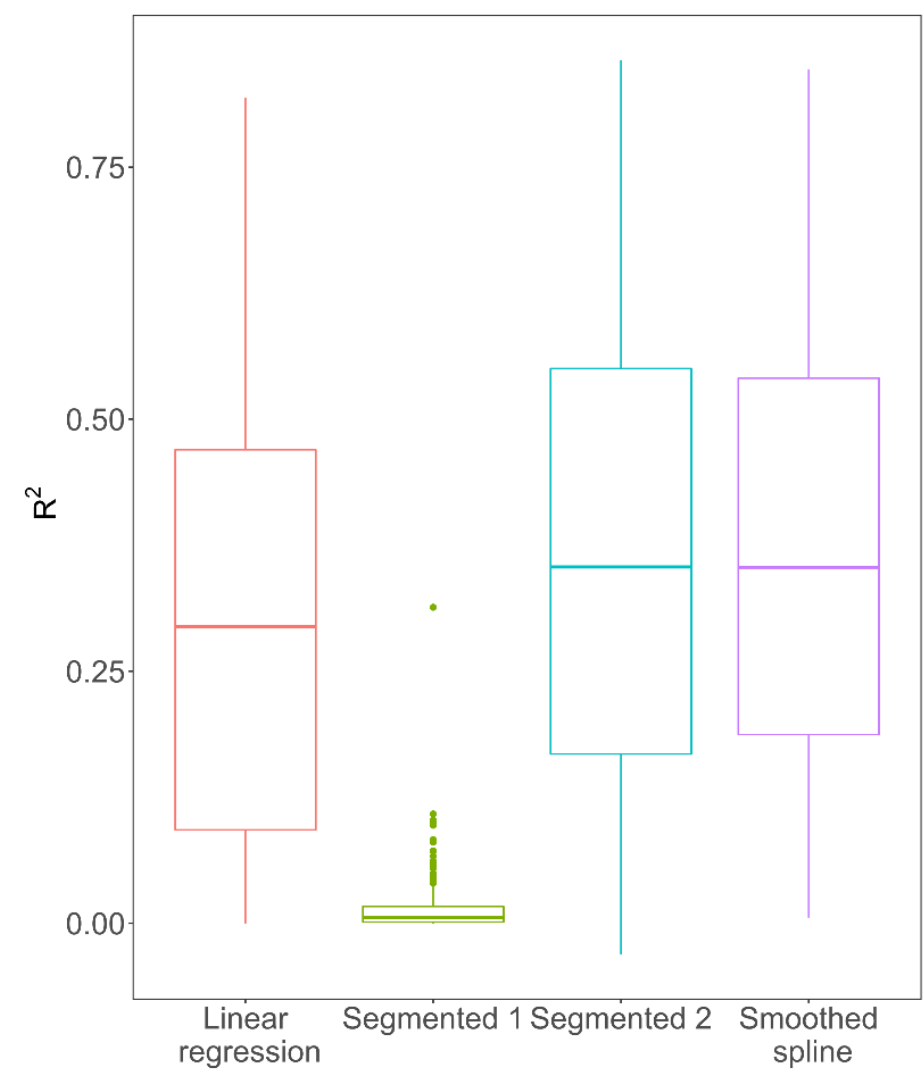

Figure B2: $\mathbf{R}^{2}$ for four models fit to $\log (\mathrm{C})-\log (\mathrm{Q})$ data of 444 French stations (Dupas et al., 2019). The smoothed spline method used for calculating curvature is compared to a simple linear regression fit, a segmented linear regression (Segmented 1) with a fixed breakpoint at the median $Q$ (Meybeck and Moatar, 2012) and a segmented regression without a fixed breakpoint as described in Marinos et al. (2020). 
https://doi.org/10.5194/hess-2021-16

(c) Author(s) 2021. CC BY 4.0 License.

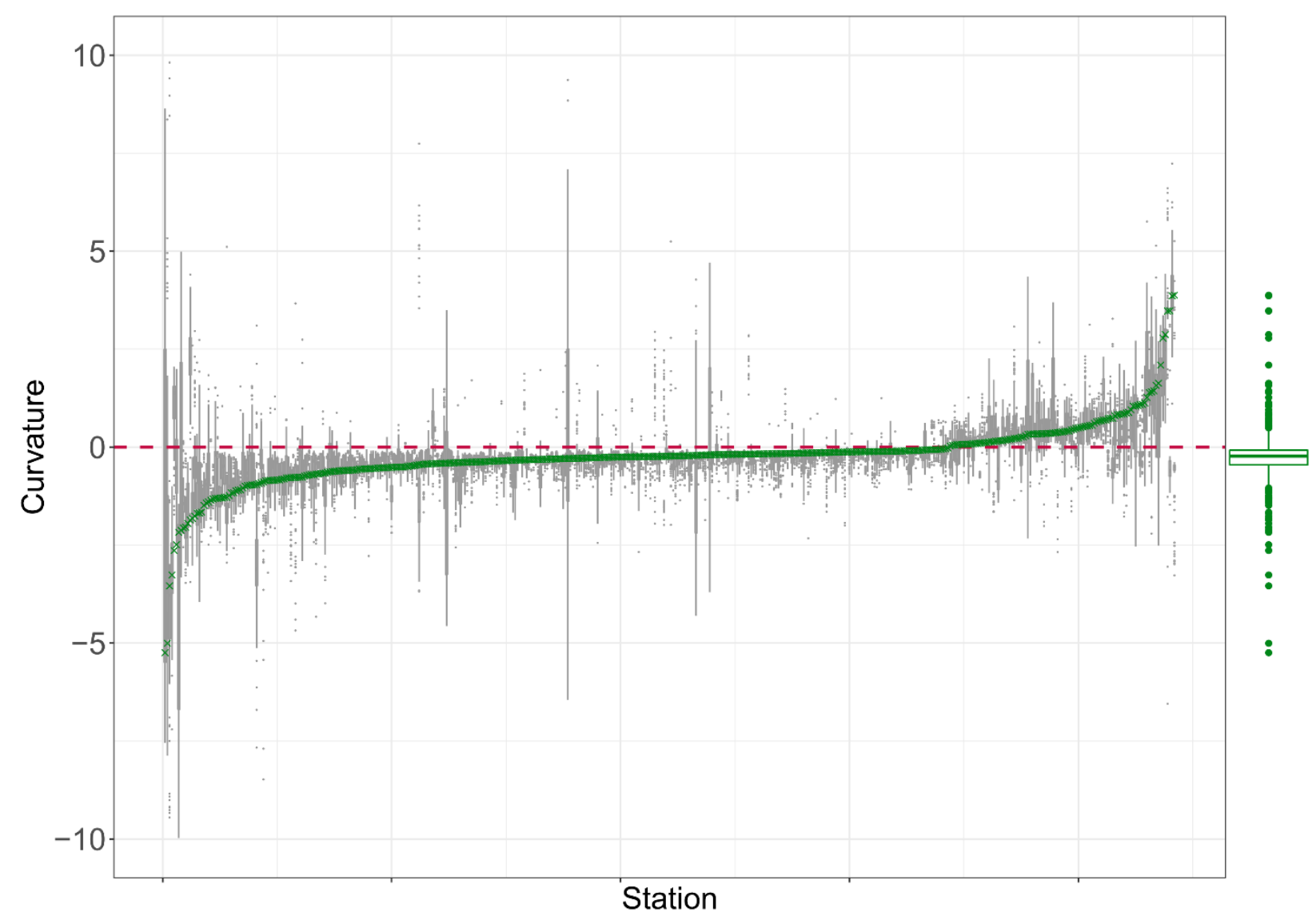

Figure B3: Curvature of nitrate $\log (C)-\log (Q)$ data for 442 French monitoring stations arranged from left to right with increasing Curvature (green crosses). For a given station, the grey boxplot represents the temporal robustness of this metric by subsampling 100 times from the original time series. The green boxplot indicates the range and distribution of all observed station Curvature values. 
https://doi.org/10.5194/hess-2021-16

Preprint. Discussion started: 19 January 2021

(c) Author(s) 2021. CC BY 4.0 License.
Hydrology and Earth System Sciences Discussions
FRONTAL VIEW

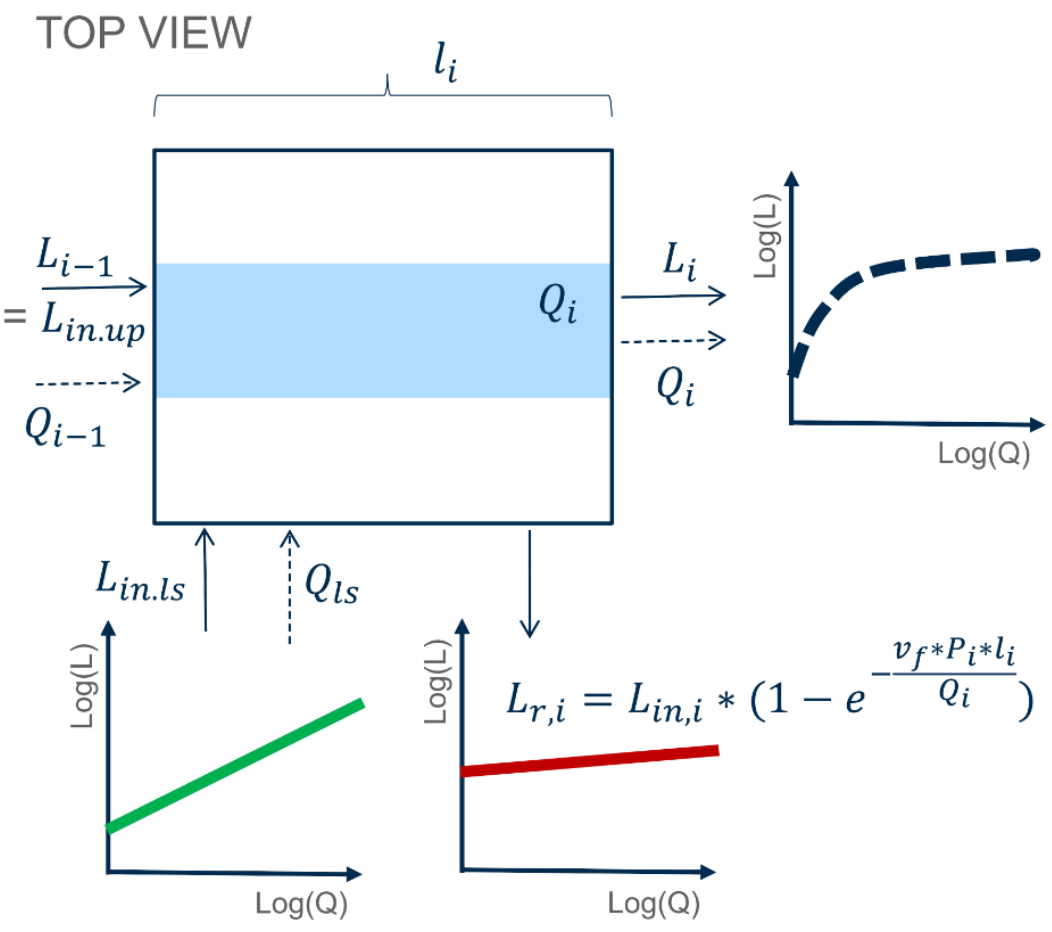

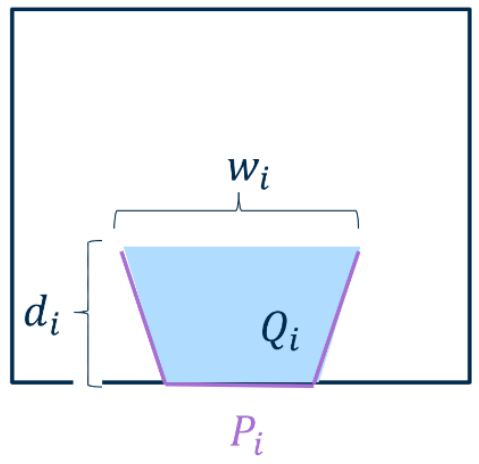

Figure B4: Network model, illustrated for one grid cell. 
https://doi.org/10.5194/hess-2021-16

Preprint. Discussion started: 19 January 2021

(c) Author(s) 2021. CC BY 4.0 License.

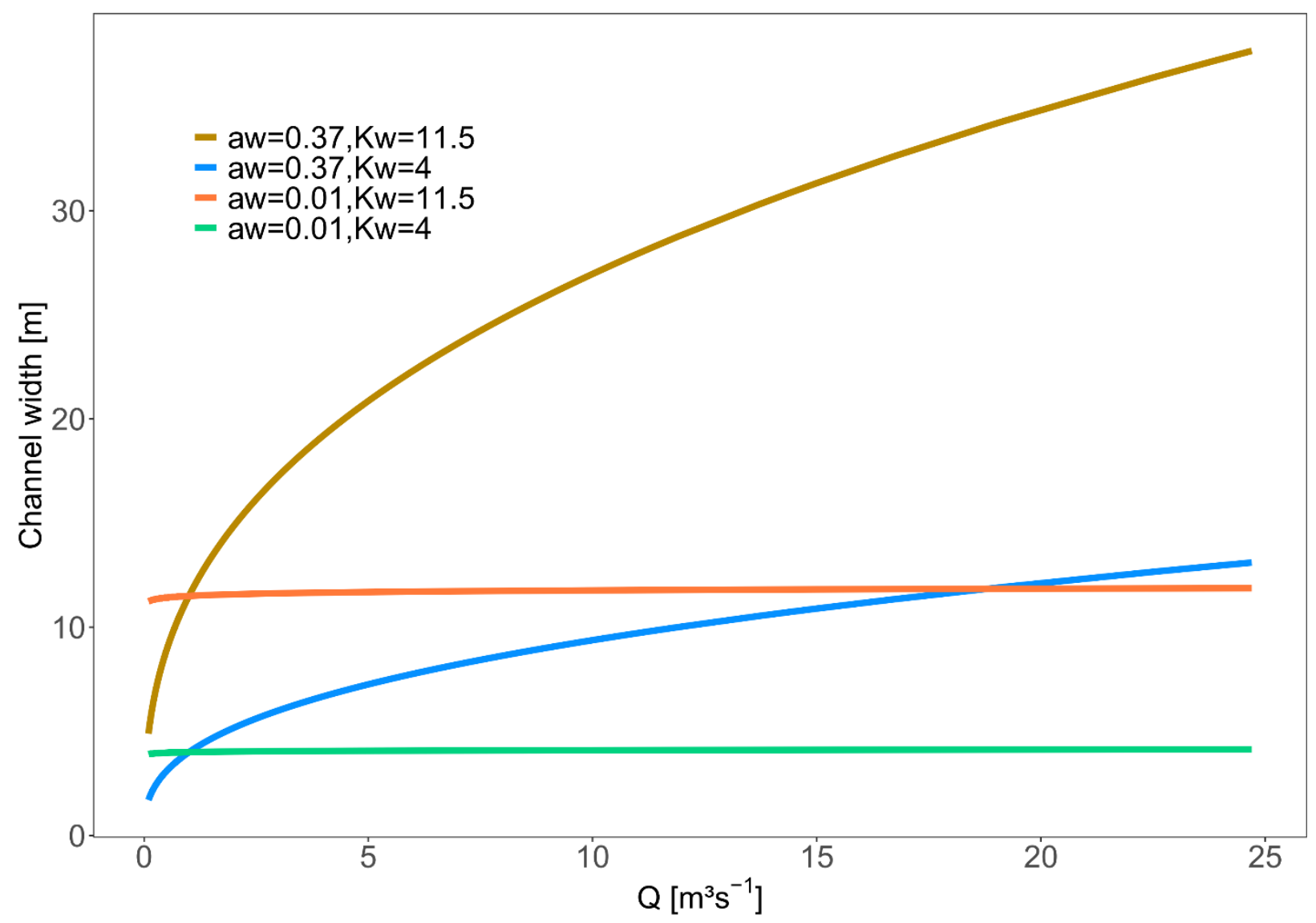

Figure B5: The effect of parameters $a_{w}$ and $K_{w}$ on the channel width illustrated for the Q timeseries at the Selke Meisdorf station. 
https://doi.org/10.5194/hess-2021-16

Preprint. Discussion started: 19 January 2021

(c) Author(s) 2021. CC BY 4.0 License.

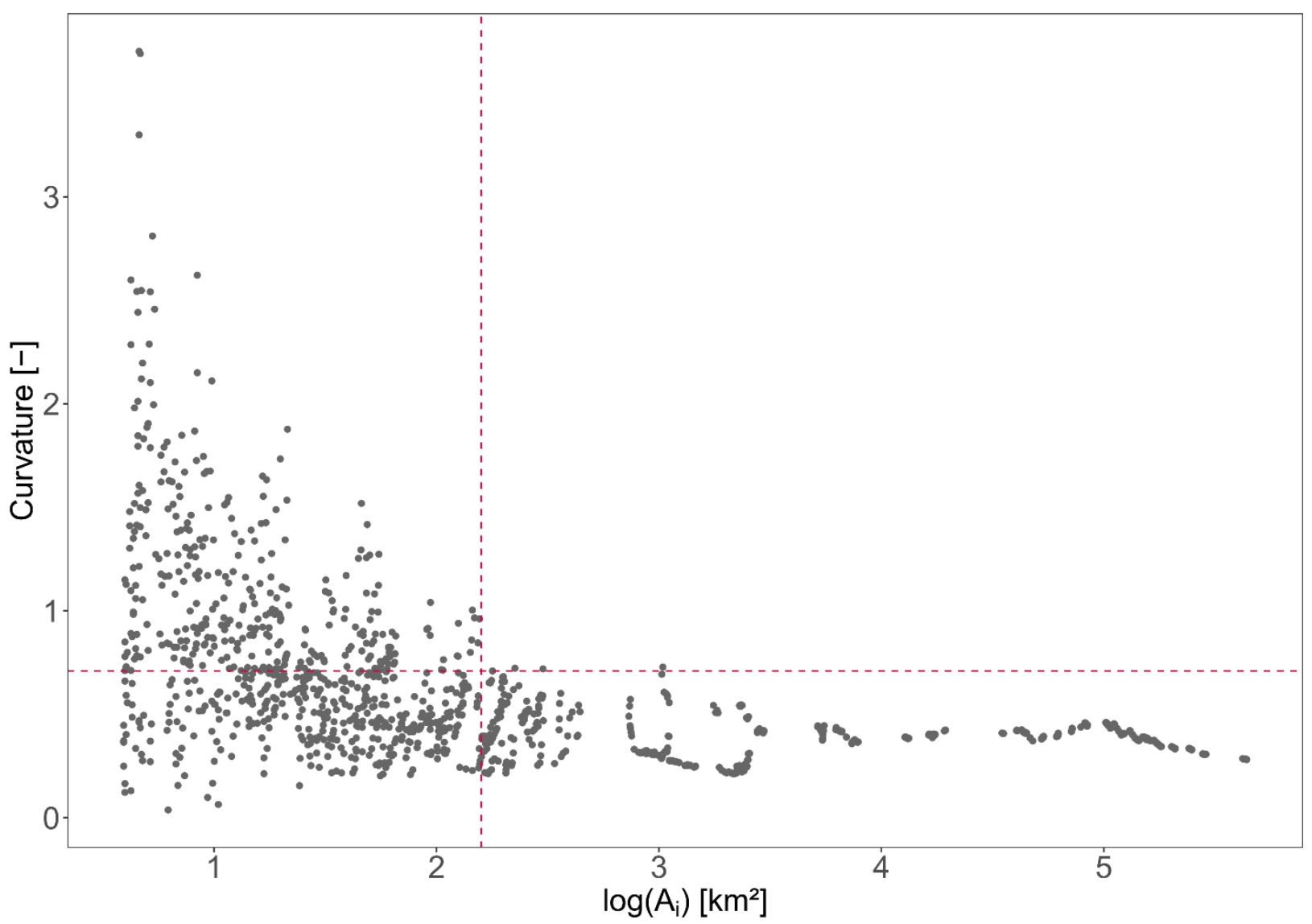

Figure B6: Curvature as a function of total drainage area $A_{i}$ (Eq. (2)) for each gridcell of the Selke Meisdorf validation run with one uniform and constant parameter set (Table C1). 
https://doi.org/10.5194/hess-2021-16

Hydrology and

Preprint. Discussion started: 19 January 2021

(c) Author(s) 2021. CC BY 4.0 License.
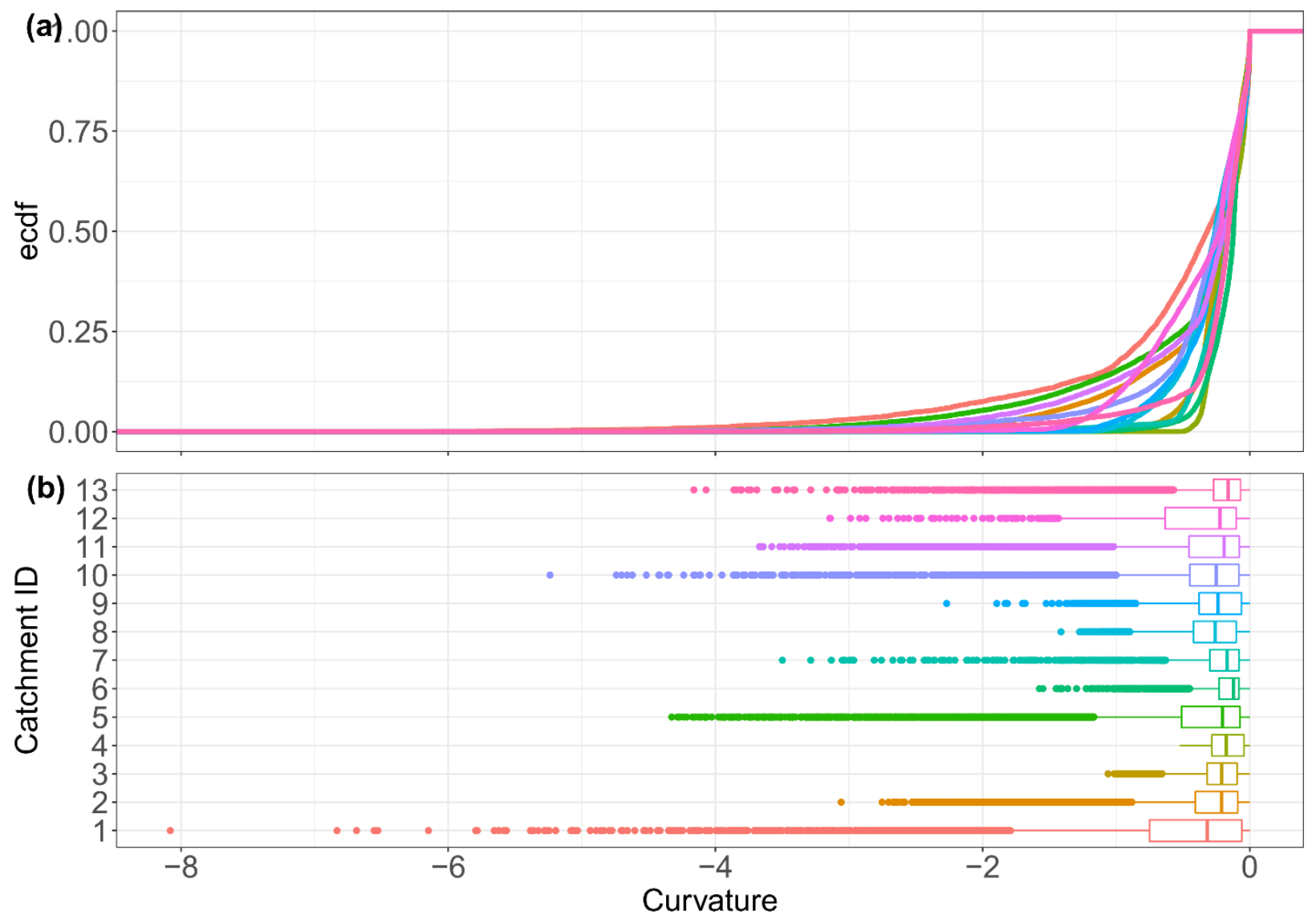

Figure B7: Curvature distributions resulting from running the same 11107 input parameter combinations in each of the 13 catchments (a) shows the elemental cumulative distribution and (b) boxplots. None of the catchments have a normally distributed Curvature set according to the Kruskal-willis $(p<0.05)$ test. 
https://doi.org/10.5194/hess-2021-16

Preprint. Discussion started: 19 January 2021

(c) Author(s) 2021. CC BY 4.0 License.
Hydrology and Earth System Sciences

Discussions (a) $\risingdotseq$ Curv low Lr.perc high $\oplus$ Curv low Lr.perc low
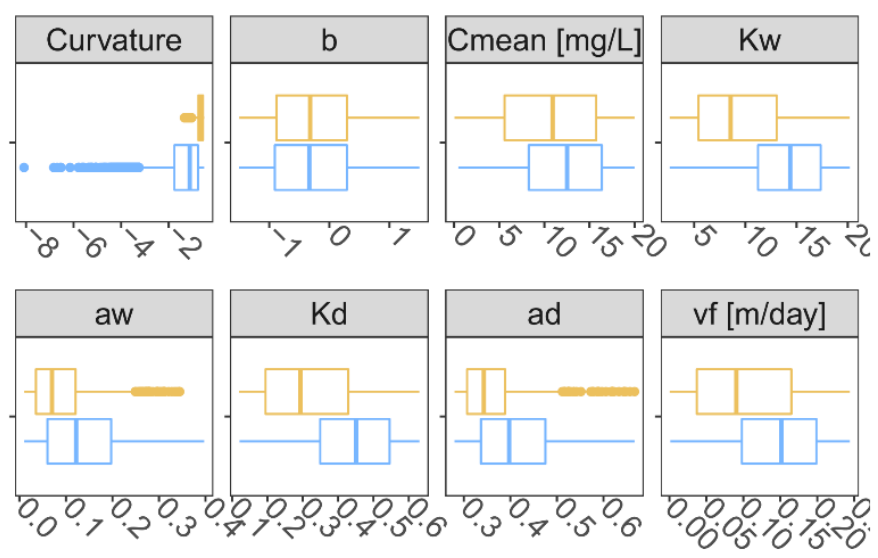

(b) $\oplus$ Curv high Lr.perc high 追 Curv high Lr.perc low
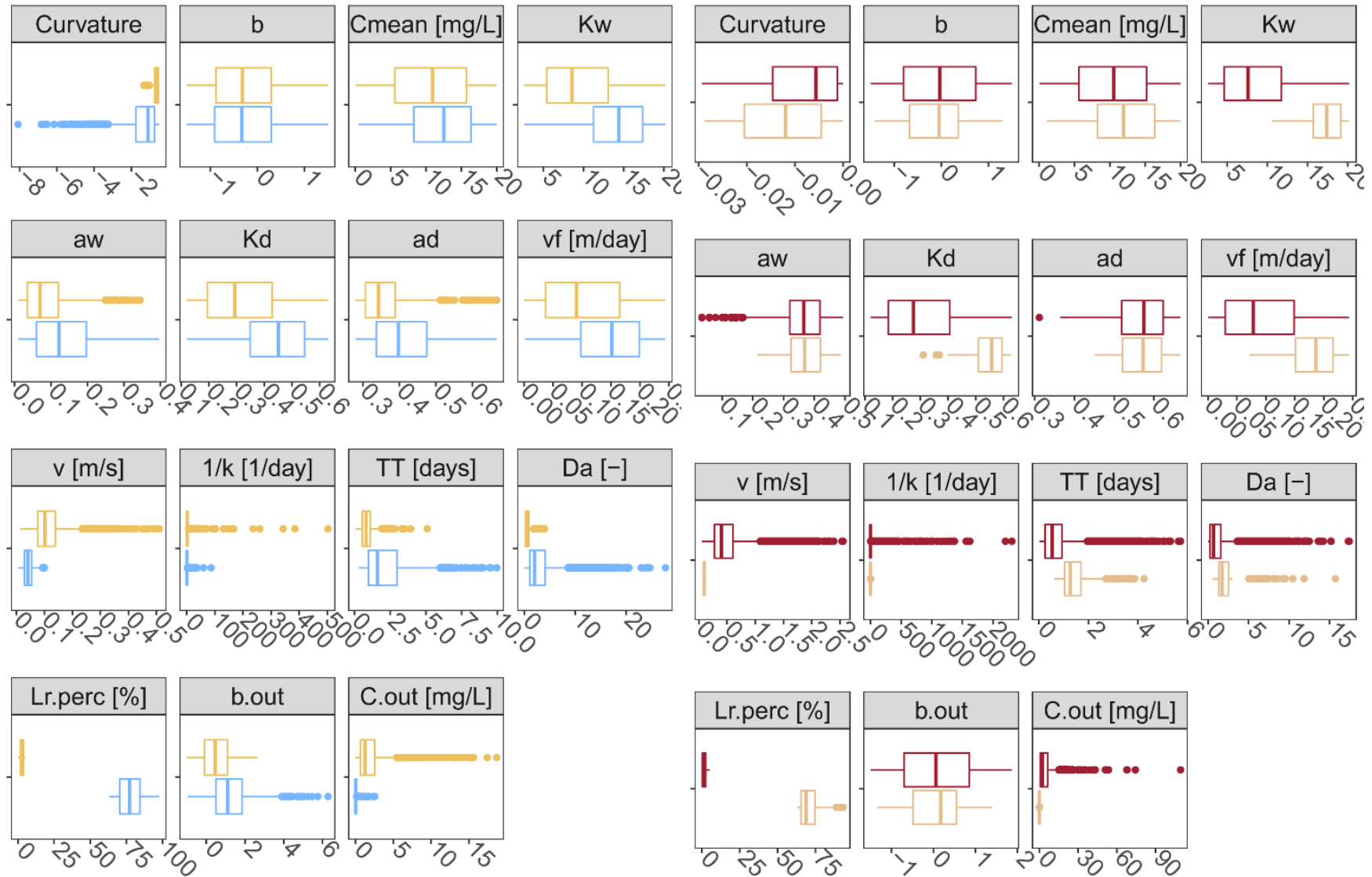

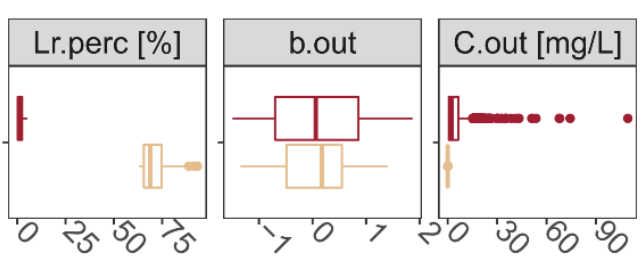

735 Figure B8: Two specific cases of Fig. 6, (a) when Curvature is low (high bending) and $L_{r . p e r c}$ is low opposed to high and (b) when Curvature is high (low bending) and $L_{r . p e r c}$ is high opposed to low. 
https://doi.org/10.5194/hess-2021-16

Preprint. Discussion started: 19 January 2021

(C) Author(s) 2021. CC BY 4.0 License.

(c) (i)
Hydrology and

Earth System

Sciences

Discussions

\section{Appendix C}

740 Table C1: Validation range for all parameters

\begin{tabular}{|cl|}
\hline Parameter & Validation Value Selke \\
\hline \hline$v_{f}$ & 0.098 \\
$b$ & 0.014 \\
$C_{\text {mean }}$ & 3.014 \\
$K_{w}$ & 2.75 \\
$a_{w}$ & 0.09 \\
$K_{d}$ & 0.17 \\
$a_{d}$ & 0.49 \\
\hline
\end{tabular}

Table C2: PAWN sensitivity indices $\mathrm{KS}_{\max }$ for all the parameters and all the catchments, together with median and coefficients of variation $(\mathrm{CV})$.

\begin{tabular}{|c|c|c|c|c|c|c|c|c|c|c|c|c|c|c|c|}
\hline \multirow[t]{2}{*}{ Parameter } & \multicolumn{13}{|c|}{ Catchment ID } & \multirow[t]{2}{*}{ Median } & \multirow[t]{2}{*}{$C V$} \\
\hline & 1 & 2 & 3 & 4 & 5 & 6 & 7 & 8 & 9 & 10 & 11 & 12 & 13 & & \\
\hline$v_{f}$ & 0.44 & 0.28 & 0.14 & 0.06 & 0.24 & 0.11 & 0.10 & 0.09 & 0.18 & 0.33 & 0.30 & 0.41 & 0.12 & 0.18 & 0.59 \\
\hline$b$ & 0.47 & 0.15 & 0.12 & 0.05 & 0.14 & 0.05 & 0.08 & 0.17 & 0.08 & 0.24 & 0.25 & 0.42 & 0.05 & 0.14 & 0.76 \\
\hline$C_{\text {mean }}$ & 0.46 & 0.21 & 0.25 & 0.13 & 0.16 & 0.18 & 0.18 & 0.07 & 0.23 & 0.25 & 0.25 & 0.34 & 0.10 & 0.19 & 0.47 \\
\hline$K_{w}$ & 0.59 & 0.41 & 0.19 & 0.11 & 0.32 & 0.16 & 0.16 & 0.13 & 0.23 & 0.39 & 0.41 & 0.50 & 0.17 & 0.23 & 0.51 \\
\hline$a_{w}$ & 0.75 & 0.58 & 0.59 & 0.58 & 0.63 & 0.61 & 0.63 & 0.66 & 0.63 & 0.65 & 0.58 & 0.60 & 0.65 & 0.62 & 0.06 \\
\hline$K_{d}$ & 0.45 & 0.32 & 0.20 & 0.08 & 0.29 & 0.15 & 0.14 & 0.09 & 0.17 & 0.46 & 0.43 & 0.53 & 0.16 & 0.20 & 0.55 \\
\hline$a_{d}$ & 0.80 & 0.39 & 0.52 & 0.52 & 0.48 & 0.29 & 0.56 & 0.53 & 0.55 & 0.51 & 0.42 & 0.48 & 0.53 & \multirow[t]{4}{*}{0.51} & \multirow[t]{4}{*}{0.22} \\
\hline Median & 0.59 & 0.39 & 0.25 & 0.13 & 0.33 & 0.18 & 0.18 & 0.17 & 0.24 & 0.43 & 0.42 & 0.50 & 0.18 & & \\
\hline$C V$ & 0.31 & 0.46 & 0.53 & 0.81 & 0.53 & 0.65 & 0.67 & 0.76 & 0.58 & 0.45 & 0.41 & 0.26 & 0.74 & & \\
\hline \multicolumn{14}{|l|}{ Variable } & & \\
\hline$D a$ & 0.53 & 0.34 & 0.30 & 0.28 & 0.39 & 0.24 & 0.22 & 0.30 & 0.21 & 0.44 & 0.37 & 0.64 & 0.21 & 0.31 & 0.38 \\
\hline$v$ & 0.95 & 0.67 & 0.39 & 0.32 & 0.69 & 0.39 & 0.55 & 0.54 & 0.64 & 0.74 & 0.70 & 0.69 & 0.62 & 0.64 & 0.26 \\
\hline
\end{tabular}

745 Table C3: Performance statistics for each of the classes for the variables $L_{r . p e r c}, \mathrm{Da}$ and $\boldsymbol{v}_{\boldsymbol{f}}$ predicted by CART.

\begin{tabular}{|c|c|c|c|c|c|c|c|c|c|}
\hline & \multicolumn{3}{|c|}{$L_{\text {r.perc }}$} & \multicolumn{3}{|c|}{$v_{f}$} & \multicolumn{3}{|c|}{$D a$} \\
\hline & class 7 & class 12 & class 18 & class 1 & class 10 & class 20 & class 3 & class 10 & class 18 \\
\hline Sensitivity & 0.63 & 0.38 & 0.94 & 0.43 & 0.00 & 0.77 & 0.63 & 0.07 & 0.82 \\
\hline Specificity & 0.91 & 0.89 & 0.69 & 0.74 & 1.00 & 0.36 & 0.75 & 0.97 & 0.54 \\
\hline Pos Pred Value & 0.77 & 0.62 & 0.61 & 0.45 & NA & 0.38 & 0.56 & 0.54 & 0.47 \\
\hline Neg Pred Value & 0.83 & 0.75 & 0.96 & 0.72 & 0.67 & 0.76 & 0.80 & 0.68 & 0.86 \\
\hline Prevalence & 0.34 & 0.32 & 0.34 & 0.34 & 0.33 & 0.33 & 0.34 & 0.33 & 0.33 \\
\hline Detection Rate & 0.21 & 0.12 & 0.32 & 0.14 & 0.00 & 0.26 & 0.21 & 0.02 & 0.27 \\
\hline
\end{tabular}


https://doi.org/10.5194/hess-2021-16

Preprint. Discussion started: 19 January 2021

(C) Author(s) 2021. CC BY 4.0 License.
Hydrology and

Earth System

Sciences

Discussions

\begin{tabular}{l|lll|llll|ll|l} 
Detection Prevalence & 0.28 & 0.12 & 0.32 & 0.32 & 0.00 & 0.68 & 0.38 & 0.04 & 0.58 \\
Balanced Accuracy & 0.77 & 0.63 & 0.82 & 0.58 & 0.50 & 0.56 & 0.69 & 0.52 & 0.68 \\
\hline
\end{tabular}

Acknowledgements This research was supported by funding from the InStream cohort and discussions with the participating scientists. Support to FS was provided by the Reduced Complexity Models project co-funded by the Helmholtz Association; and FS and RK acknowledge the Advanced Earth Modelling Capacity (ESM) project funded by the Helmholtz Association. We further thank Remi Dupas for providing French nitrate CQ data and Pia Ebeling for the German catchments characteristics data.

Author contributions JD and AM designed the study together with RK. JD developed the model code, carried out the

755 simulations and interpreted them. FS provided help with the PAWN method. JD and AM prepared the manuscript draft and all co-authors contributed to reviewing and editing the manuscript.

Competing interests The authors declare that they have no conflict of interest.

\section{References}

760 Abbott, B. W., Gruau, G., Zarnetske, J. P., Moatar, F., Barbe, L., Thomas, Z., Fovet, O., Kolbe, T., Gu, S., Pierson-Wickmann, A. C., Davy, P., and Pinay, G.: Unexpected spatial stability of water chemistry in headwater stream networks, Ecol Lett, 21, 296-308, 10.1111/ele.12897, 2018.

Aguilera, R., Marcé, R., and Sabater, S.: Modeling nutrient retention at the watershed scale: Does small stream research apply to the whole river network?, J Geophys Res-Biogeo, 118, 728-740, 10.1002/jgrg.20062, 2013.

765 Alexander, R. B., Böhlke, J. K., Boyer, E. W., David, M. B., Harvey, J. W., Mulholland, P. J., Seitzinger, S. P., Tobias, C. R., Tonitto, C., and Wollheim, W. M.: Dynamic modeling of nitrogen losses in river networks unravels the coupled effects of hydrological and biogeochemical processes, Biogeochemistry, 93, 91-116, 10.1007/s10533-008-9274-8, 2009.

Alexander, R. B., Smith, R. A., and Schwarz, G. E.: Effect of stream channel size on the delivery of nitrogen to the Gulf of Mexico, Nature, 403, 758-761, 10.1038/35001562, 2000.

770 Ameli, A. A., Beven, K., Erlandsson, M., Creed, I. F., McDonnell, J. J., and Bishop, K.: Primary weathering rates, water transit times, and concentration-discharge relations: A theoretical analysis for the critical zone, Water Resour Res, 53, 942-960, 10.1002/2016wr019448, 2017.

Andreadis, K. M., Schumann, G. J. P., and Pavelsky, T.: A simple global river bankfull width and depth database, A simple global river bankfull width and depth database, 49, 7164-7168, 10.1002/wrcr.20440, 2013. 

averaging of in-stream solute removal dynamics, Water Resour Res, 47, 10.1029/2010wr010196, 2011.

Bergstrom, A., McGlynn, B., Mallard, J., and Covino, T.: Watershed structural influences on the distributions of stream network water and solute travel times under baseflow conditions, Hydrol Process, 30, 2671-2685, 10.1002/hyp.10792, 2016. Bertuzzo, E., Helton, A. M., Hall, R. O., and Battin, T. J.: Scaling of dissolved organic carbon removal in river networks, Adv Water Resour, 110, 136-146, 10.1016/j.advwatres.2017.10.009, 2017.

Beusen, A. H. W., Bouwman, A. F., Van Beek, L. P. H., Mogollon, J. M., and Middelburg, J. J.: Global riverine N and P transport to ocean increased during the 20th century despite increased retention along the aquatic continuum, Biogeosciences, 13, 2441-2451, 10.5194/bg-13-2441-2016, 2016.

Bieroza, M. Z., Heathwaite, A. L., Bechmann, M., Kyllmar, K., and Jordan, P.: The concentration-discharge slope as a tool for water quality management, Sci Total Environ, 630, 738-749, 10.1016/j.scitotenv.2018.02.256, 2018.

Billen, G., Lancelot, C., and Meybeck, M.: N, P and Si retention along the aquatic continuum from land to ocean., N, P and Si retention along the aquatic continuum from land to ocean., 1 ed., 19-44, 1991.

Birgand, F., Skaggs, R. W., Chescheir, G. M., and Gilliam, J. W.: Nitrogen removal in streams of agricultural catchments - A literature review, Crit Rev Env Sci Tec, 37, 381-487, 10.1080/10643380600966426, 2007.

790 Bouwman, A. F., Bierkens, M. F. P., Griffioen, J., Hefting, M. M., Middelburg, J. J., Middelkoop, H., and Slomp, C. P.: Nutrient dynamics, transfer and retention along the aquatic continuum from land to ocean: towards integration of ecological and biogeochemical models, Biogeosciences, 9, 8733-8782, 10.5194/bgd-9-8733-2012, 2012.

Boyer, E. W., Alexander, R. B., Parton, W. J., Li, C. S., Butterbach-Bahl, K., Donner, S. D., Skaggs, R. W., and Del Gross, S. J.: Modeling denitrification in terrestrial and aquatic ecosystems at regional scales, Ecol Appl, 16, 2123-2142, 10.1890/1051795 0761(2006)016[2123:Mditaa]2.0.Co;2, 2006.

Breiman, L., Friedman, J., Stone, C. J., and Olshen, R. A.: Classification and Regression Trees, Chapman \& Hall, London:, 1984.

Canfield, D. E., Glazer, A. N., and Falkowski, P. G.: The evolution and future of Earth's nitrogen cycle, Science, 330, 192196, 10.1126/science.1186120, 2010.

800 Diamond, J. S. and Cohen, M. J.: Complex patterns of catchment solute-discharge relationships for coastal plain rivers, Hydrol Process, 32, 388-401, 10.1002/hyp.11424, 2018.

Dingman, S. L.: Analytical derivation of at-a-station hydraulic-geometry relations, J Hydrol, 334, 17-27, 10.1016/j.jhydrol.2006.09.021, 2007.

Doyle, M. W.: Incorporating hydrologic variability into nutrient spiraling, J Geophys Res, 110, 10.1029/2005jg000015, 2005.

805 Dupas, R., Minaudo, C., and Abbott, B. W.: Stability of spatial patterns in water chemistry across temperate ecoregions, Environ Res Lett, 14, 10.1088/1748-9326/ab24f4, 2019. 
Dupas, R., Musolff, A., Jawitz, J., Rao, P. S. C., Jager, C. G., Fleckenstein, J. H., Rode, M., and Borchardt, D.: Carbon and nutrient export regimes from headwater catchments to downstream reaches, Biogeosciences, 14, 4391-4407, 10.5194/bg-144391-2017, 2017.

Durand, P., Breuer, L., Johnes, P. J., Billen, G., Butturini, A., Pinay, G., and Wright, R.: Nitrogen processes in aquatic ecosystems. In: The European Nitrogen Assessment: Sources, Effects and Policy Perspectives, Sutton, M., Howard, C., Erisman, J., Billen, G., Bleeker, A., Grennfelt, P., and al., e. (Eds.), Cambridge University Press, Cambridge, 2011.

Ebeling, P.: CCDB - catchment characteristics data base Germany. HydroShare, 2020a.

Ebeling, P.: WQQDB - water quality metrics for catchments across Germany HydroShare, $2020 \mathrm{~b}$.

Ebeling, P., Kumar, R., Weber, M., Knoll, L., Fleckenstein, J. H., and Musolff, A.: Archetypes and Controls of Riverine Nutrient Export Across German Catchments, Water Resour Res, doi: 10.1002/essoar.10503375.1, 2020 rev. 10.1002/essoar.10503375.1, $2020 \mathrm{rev}$.

EEA: DEM over Europe from the GMES RDA project (EU-DEM, resolution 25m) - version 1, Oct. 2013, edited, European Environmental Agency, 2013.

820 Ehrhardt, S., Kumar, R., Fleckenstein, J. H., Attinger, S., and Musolff, A.: Trajectories of nitrate input and output in three nested catchments along a land use gradient, Hydrol Earth Syst Sc, 23, 3503-3524, 10.5194/hess-23-3503-2019, 2019.

Ensign, S. H. and Doyle, M. W.: Nutrient spiraling in streams and river networks, J Geophys Res-Biogeo, 111, 10.1029/2005jg000114, 2006.

Ensign, S. H., McMillan, S. K., Thompson, S. P., and Piehler, M. F.: Nitrogen and phosphorus attenuation within the stream network of a coastal, agricultural watershed, J Environ Qual, 35, 1237-1247, 10.2134/jeq2005.0341, 2006.

ESRI: ArcGIS Desktop: Release 10. Redlands, CA: Environmental Systems Research Institute., 2011.

Fisher, S. G., Sponseller, R. A., and Heffernan, J. B.: Horizons in stream biogeochemistry: Flowpaths to progress, Ecology, 85, 2369-2379, 10.1890/03-0244, 2004.

Galloway, J. N., Schlesinger, W. H., Levy, H., Michaels, A., and Schnoor, J. L.: Nitrogen fixation: Anthropogenic enhancement-environmental response, Global Biogeochem Cy, 9, 235-252, 10.1029/95gb00158, 1995.

Godsey, S. E., Kirchner, J. W., and Clow, D. W.: Concentration-discharge relationships reflect chemostatic characteristics of US catchments, Hydrol Process, 23, 1844-1864, 10.1002/hyp.7315, 2009.

Gomez-Velez, J. D., Harvey, J., Cardenas, M. B., and Kiel, B.: Denitrification in the Mississippi River network controlled by flow through river bedforms, Nat Geosci, 8, 941-U975, 10.1038/Ngeo2567, 2015.

835 Hall, R. O., Tank, J. L., Sobota, D. J., and Mulholland, P. J.: Nitrate removal in stream ecosystems measured by $15 \mathrm{~N}$ addition experiments: Total uptake, Limnol Oceanogr, 54, 653-665, 10.4319/lo.2009.54.3.0653, 2009.

Helton, A. M., Hall, R. O., and Bertuzzo, E.: How network structure can affect nitrogen removal by streams, Freshwater Biol, 63, 128-140, 10.1111/fwb.12990, 2018.

Helton, A. M., Poole, G. C., Meyer, J. L., Wollheim, W. M., Peterson, B. J., Mulholland, P. J., Bernhardt, E. S., Stanford, J. 
McDowell, W. H., Potter, J. D., Tank, J. L., Thomas, S. M., Valett, H. M., Webster, J. R., and Zeglin, L.: Thinking outside the channel: modeling nitrogen cycling in networked river ecosystems, Front Ecol Environ, 9, 229-238, 10.1890/080211, 2010.

Hensley, R. T., Cohen, M. J., and Korhnak, L. V.: Inferring nitrogen removal in large rivers from high-resolution longitudinal profiling, Limnol Oceanogr, 59, 1152-1170, 10.4319/lo.2014.59.4.1152, 2014.

Horton, R. E.: Erosional Development of Streams and Their Drainage Basins - Hydrophysical Approach to Quantitative Morphology, Geol Soc Am Bull, 56, 275-370, 10.1130/0016-7606(1945)56[275:edosat]2.0.co;2, 1945.

Jarvie, H. P., Sharpley, A. N., Kresse, T., Hays, P. D., Williams, R. J., King, S. M., and Berry, L. G.: Coupling High-Frequency Stream Metabolism and Nutrient Monitoring to Explore Biogeochemical Controls on Downstream Nitrate Delivery, Environ Sci Technol, 52, 13708-13717, 10.1021/acs.est.8b03074, 2018.

850 Jawitz, J. W. and Mitchell, J.: Temporal inequality in catchment discharge and solute export, Water Resour Res, 47, 10.1029/2010wr010197, 2011.

Kiel, B. A. and Cardenas, M. B.: Lateral hyporheic exchange throughout the Mississippi River network, Nat Geosci, 7, 413417, 10.1038/Ngeo2157, 2014.

Kirchner, J. W., Feng, X., and Neal, C.: Fractal stream chemistry and its implications for contaminant transport in catchments, 855 Nature, 403, 524-527, 10.1038/35000537, 2000.

Klemes, V.: Dilettantism in Hydrology - Transition or Destiny, Water Resour Res, 22, S177-S188, 10.1029/WR022i09Sp0177S, 1986.

Kuhn, M.: caret: Classification and Regression Training. 2020.

Kumar, R., Hesse, F., Rao, P. S. C., Musolff, A., Jawitz, J. W., Sarrazin, F., Samaniego, L., Fleckenstein, J. H., Rakovec, O.,

860 Thober, S., and Attinger, S.: Strong hydroclimatic controls on vulnerability to subsurface nitrate contamination across Europe, Nat Commun, 11, 6302, 10.1038/s41467-020-19955-8, 2020.

Kunz, J. V., Hensley, R., Brase, L., Borchardt, D., and Rode, M.: High frequency measurements of reach scale nitrogen uptake in a fourth order river with contrasting hydromorphology and variable water chemistry (Weisse Elster, Germany), Water Resour Res, 53, 328-343, 10.1002/2016wr019355, 2017.

865 Langbein, W. B. and Leopold, L. B.: Quasi-Equilibrium States in Channel Morphology, Am J Sci, 262, 782-\&, 10.2475/ajs.262.6.782, 1964.

Leopold, L. B. and Maddock, T.: The hydraulic geometry of stream channels and some physiographic implications, Washington, D.C., 1953.

Li, L., Sullivan, P. L., Benettin, P., Cirpka, O. A., Bishop, K., Brantley, S. L., Knapp, J. L. A., Meerveld, I., Rinaldo, A., 870 Seibert, J., Wen, H., and Kirchner, J. W.: Toward catchment hydro-biogeochemical theories, WIREs Water, 8, $10.1002 /$ wat2.1495, 2020.

Lindgren, G. A. and Destouni, G.: Nitrogen loss rates in streams: Scale-dependence and up-scaling methodology, Geophys Res Lett, 31, 1-4, 10.1029/2004g1019996, 2004. 
Marce, R. and Armengol, J.: Modeling nutrient in-stream processes at the watershed scale using Nutrient Spiralling metrics,

Hydrol Earth Syst Sc, 13, 953-967, 10.5194/hess-13-953-2009, 2009.

Marinos, R. E., Van Meter, K. J., and Basu, N. B.: Is the River a Chemostat?: Scale Versus Land Use Controls on Nitrate Concentration-Discharge Dynamics in the Upper Mississippi River Basin, Geophys Res Lett, 47, 10.1029/2020g1087051, 2020 .

McDonnell, J. J., Sivapalan, M., Vaché, K., Dunn, S., Grant, G., Haggerty, R., Hinz, C., Hooper, R., Kirchner, J., Roderick,

M. L., Selker, J., and Weiler, M.: Moving beyond heterogeneity and process complexity: A new vision for watershed hydrology, Water Resour Res, 43, 10.1029/2006wr005467, 2007.

Meybeck, M. and Moatar, F.: Daily variability of river concentrations and fluxes: indicators based on the segmentation of the rating curve, Hydrol Process, 26, 1188-1207, 10.1002/hyp.8211, 2012.

Minaudo, C., Dupas, R., Gascuel-Odoux, C., Roubeix, V., Danis, P.-A., and Moatar, F.: Seasonal and event-based concentration-discharge relationships to identify catchment controls on nutrient export regimes, Adv Water Resour, 131, 10.1016/j.advwatres.2019.103379, 2019.

Mineau, M. M., Wollheim, W. M., and Stewart, R. J.: An index to characterize the spatial distribution of land use within watersheds and implications for river network nutrient removal and export, Geophys Res Lett, 42, 6688-6695, $10.1002 / 2015 \mathrm{gl} 1064965,2015$.

890 Moatar, F., Abbott, B. W., Minaudo, C., Curie, F., and Pinay, G.: Elemental properties, hydrology, and biology interact to shape concentration-discharge curves for carbon, nutrients, sediment, and major ions, Water Resour Res, 53, 1270-1287, 10.1002/2016wr019635, 2017.

Mueller, C., Musolff, A., Strachauer, U., Brauns, M., Tarasova, L., Merz, R., and Knöller, K.: Tomography of anthropogenic nitrate contribution along a mesoscale river, Sci Total Environ, 615, 773-783, 10.1016/j.scitotenv.2017.09.297, 2018.

Mulholland, P. J., Helton, A. M., Poole, G. C., Hall, R. O., Hamilton, S. K., Peterson, B. J., Tank, J. L., Ashkenas, L. R., Cooper, L. W., Dahm, C. N., Dodds, W. K., Findlay, S. E., Gregory, S. V., Grimm, N. B., Johnson, S. L., McDowell, W. H., Meyer, J. L., Valett, H. M., Webster, J. R., Arango, C. P., Beaulieu, J. J., Bernot, M. J., Burgin, A. J., Crenshaw, C. L., Johnson, L. T., Niederlehner, B. R., O'Brien, J. M., Potter, J. D., Sheibley, R. W., Sobota, D. J., and Thomas, S. M.: Stream denitrification across biomes and its response to anthropogenic nitrate loading, Nature, 452, 202-205, 10.1038/nature06686, 9002008.

Mulholland, P. J. and Tank, J. L.: Can uptake length in streams be determined by nutrient addition experiments? Results from an interbiome comparison study, J N Am Benthol Soc, 21, 544-560, 10.2307/1468429, 2002.

Musolff, A.: WQQDB - water quality and quantity data base Germany: metadata. Hydroshare, 2020.

Musolff, A., Fleckenstein, J. H., Rao, P. S. C., and Jawitz, J. W.: Emergent archetype patterns of coupled hydrologic and 905 biogeochemical responses in catchments, Geophys Res Lett, 44, 4143-4151, 10.1002/2017gl072630, 2017.

Newbold, J. D., Elwood, J. W., Oneill, R. V., and Vanwinkle, W.: Measuring Nutrient Spiralling in Streams, Can J Fish Aquat Sci, 38, 860-863, DOI 10.1139/f81-114, 1981. 
O’Brien, J. M., Dodds, W. K., Wilson, K. C., Murdock, J. N., and Eichmiller, J.: The saturation of N cycling in Central Plains streams: $15 \mathrm{~N}$ experiments across a broad gradient of nitrate concentrations, Biogeochemistry, 84, 31-49, 10.1007/s10533-0079073-7, 2007.

Ocampo, C. J., Oldham, C. E., and Sivapalan, M.: Nitrate attenuation in agricultural catchments: Shifting balances between transport and reaction, Water Resour Res, 42, 10.1029/2004wr003773, 2006.

Oldham, C. E., Farrow, D. E., and Peiffer, S.: A generalized Damköhler number for classifying material processing in hydrological systems, Hydrol Earth Syst Sc, 17, 1133-1148, 10.5194/hess-17-1133-2013, 2013.

915 Pennino, M. J., Kaushal, S. S., Beaulieu, J. J., Mayer, P. M., and Arango, C. P.: Effects of urban stream burial on nitrogen uptake and ecosystem metabolism: implications for watershed nitrogen and carbon fluxes, Biogeochemistry, 121, 247-269, 10.1007/s10533-014-9958-1, 2014.

Peterson, B. J., Wollheim, W. M., Mulholland, P. J., Webster, J. R., Meyer, J. L., Tank, J. L., Marti, E., Bowden, W. B., Valett, H. M., Hershey, A. E., McDowell, W. H., Dodds, W. K., Hamilton, S. K., Gregory, S., and Morrall, D. D.: Control of nitrogen export from watersheds by headwater streams, Science, 292, 86-90, 10.1126/science.1056874, 2001.

Pianosi, F., Sarrazin, F., and Wagener, T.: A Matlab toolbox for Global Sensitivity Analysis, Environ Modell Softw, 70, 8085, 10.1016/j.envsoft.2015.04.009, 2015.

Pianosi, F. and Wagener, T.: Distribution-based sensitivity analysis from a generic input-output sample, Environ Modell Softw, 108, 197-207, 10.1016/j.envsoft.2018.07.019, 2018.

Pianosi, F. and Wagener, T.: A simple and efficient method for global sensitivity analysis based on cumulative distribution functions, Environ Modell Softw, 67, 1-11, 10.1016/j.envsoft.2015.01.004, 2015.

Pinay, G., Peiffer, S., De Dreuzy, J. R., Krause, S., Hannah, D. M., Fleckenstein, J. H., Sebilo, M., Bishop, K., and HubertMoy, L.: Upscaling Nitrogen Removal Capacity from Local Hotspots to Low Stream Orders' Drainage Basins, Ecosystems, 18, 1101-1120, 10.1007/s10021-015-9878-5, 2015.

930 Pressley, A. N.: Elementary Differential Geometry, 2010.

R Core Team: R: A language and environment for statistical computing. . R Foundation for Statistical Computing, Vienna, Austria, 2013.

Risse-Buhl, U., Anlanger, C., Kalla, K., Neu, T. R., Noss, C., Lorke, A., and Weitere, M.: The role of hydrodynamics in shaping the composition and architecture of epilithic biofilms in fluvial ecosystems, Water Res, 127, 211-222, 935 10.1016/j.watres.2017.09.054, 2017.

Rode, M., Halbedel Nee Angelstein, S., Anis, M. R., Borchardt, D., and Weitere, M.: Continuous In-Stream Assimilatory Nitrate Uptake from High-Frequency Sensor Measurements, Environ Sci Technol, 50, 5685-5694, 10.1021/acs.est.6b00943, 2016.

Runkel, R. L. and Bencala, K. E.: Transport of reacting solutes in rivers and streams. In: Environmental Hydrology, Water 940 Science and Technology Library, 1995. 
Schlesinger, W. H., Reckhow, K. H., and Bernhardt, E. S.: Global change: The nitrogen cycle and rivers, Water Resour Res, 42, 10.1029/2005wr004300, 2006.

Seitzinger, S. P., Styles, R. V., Boyer, E. W., Alexander, R. B., Billen, G., Howarth, R. W., Mayer, B., and Van Breemen, N.: Nitrogen retention in rivers: model development and application to watersheds in the northeastern U.S.A., Biogeochemistry, 57/58, 199-237, 10.1023/A:1015745629794, 2002.

Seybold, E. and McGlynn, B.: Hydrologic and biogeochemical drivers of dissolved organic carbon and nitrate uptake in a headwater stream network, Biogeochemistry, 138, 23-48, 10.1007/s10533-018-0426-1, 2018.

Stream Solute Workshop: Concepts and Methods for Assessing Solute Dynamics in Stream Ecosystems, J N Am Benthol Soc, 9, 95-119, 10.2307/1467445, 1990.

950 Vanni, M. J.: Nutrient Cycling by Animals in Freshwater Ecosystems, Nutrient Cycling by Animals in Freshwater Ecosystems, 33, 341-370, 10.1146/annurev.ecolsys.33.010802.150519, 2002.

Vanni, M. J. and McIntyre, P. B.: Predicting nutrient excretion of aquatic animals with metabolic ecology and ecological stoichiometry: a global synthesis, Ecology, 97, 3460-3471, 10.1002/ecy.1582, 2016.

Wei, T. and Simko, V.: R package "corrplot": Visualization of a Correlation Matrix 2020.

955 Winter, C., Lutz, S. R., Musolff, A., Kumar, R., Weber, M., and Fleckenstein, J. H.: Disentangling the impact of catchment heterogeneity on nitrate export dynamics from event to long-term time scales, Water Resour Res, doi: 10.1002/essoar.10503228.1, 2020. 10.1002/essoar.10503228.1, 2020.

Wollheim, W. M., Bernal, S., Burns, D. A., Czuba, J. A., Driscoll, C. T., Hansen, A. T., Hensley, R. T., Hosen, J. D., Inamdar, S., Kaushal, S. S., Koenig, L. E., Lu, Y. H., Marzadri, A., Raymond, P. A., Scott, D., Stewart, R. J., Vidon, P. G., and Wohl,

960 E.: River network saturation concept: factors influencing the balance of biogeochemical supply and demand of river networks, Biogeochemistry, 141, 503-521, 10.1007/s10533-018-0488-0, 2018.

Wollheim, W. M., Mulukutla, G. K., Cook, C., and Carey, R. O.: Aquatic Nitrate Retention at River Network Scales Across Flow Conditions Determined Using Nested In Situ Sensors, Water Resour Res, 53, 9740-9756, 10.1002/2017wr020644, 2017. Wollheim, W. M., Peterson, B. J., Thomas, S. M., Hopkinson, C. H., and Vörösmarty, C. J.: Dynamics of N removal over 965 annual time periods in a suburban river network, J Geophys Res, 113, 10.1029/2007jg000660, 2008.

Wollheim, W. M., Vörösmarty, C. J., Peterson, B. J., Seitzinger, S. P., and Hopkinson, C. S.: Relationship between river size and nutrient removal, Geophys Res Lett, 33, 10.1029/2006gl025845, 2006.

Yang, X., Jomaa, S., Buttner, O., and Rode, M.: Autotrophic nitrate uptake in river networks: A modeling approach using continuous high-frequency data, Water Res, 157, 258-268, 10.1016/j.watres.2019.02.059, 2019.

970 Yang, X. Q., Jomaa, S., Zink, M., Fleckenstein, J. H., Borchardt, D., and Rode, M.: A New Fully Distributed Model of Nitrate Transport and Removal at Catchment Scale, Water Resour Res, 54, 5856-5877, 10.1029/2017wr022380, 2018.

Zarnetske, J. P., Haggerty, R., Wondzell, S. M., and Baker, M. A.: Dynamics of nitrate production and removal as a function of residence time in the hyporheic zone, J Geophys Res, 116, 10.1029/2010jg001356, 2011. 